\title{
Advancing girls' education in light of COVID-19 in East Africa: A synthesis report
}

Population Council

Regional Education Learning Initiative

Mannion Daniels

Follow this and additional works at: https://knowledgecommons.popcouncil.org/departments_sbsr-pgy How does access to this work benefit you? Let us know!

\section{Recommended Citation}

Population Council, Regional Education Learning Initiative, and Mannion Daniels. 2021. "Advancing girls' education in light of COVID-19 in East Africa: A synthesis report." Nairobi: Population Council. 


\section{ADVANCING GIRLS' \\ EDUCATION IN LIGHT OF \\ COVID-19 IN EAST AFRICA \\ A Synthesis Report}

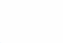


POPULATION COUNCIL KENYA (PC Kenya) seeks to improve the well-being and health of current and future generations and to help achieve a humane, equitable, and sustainable balance between people and resources. We develop sustainable program solutions that respond to girls' educational needs and build their social, economic, and health assets; improve sexual and reproductive health and rights; reduce HIV transmission; prevent and respond to sexual and gender-based violence (SGBV); assess various serviceintegration models; and strengthen evidence for program related to unintended pregnancy. Since 1993, we have given voice and visibility to the most vulnerable by increasing awareness of the problems they face and offering evidence-based solutions and innovations that respond to local social context. PC Kenya is a locally registered entity and is an affiliate of Population Council, Inc., a global leader in high-quality program-relevant research.

Suggested citation: Population Council, Regional Education Learning Initiative, \& Mannion Daniels. (2021). Advancing Girls' Education in Light of COVID-19 in East Africa: A Synthesis Report. Nairobi, Kenya: Population Council.

Any part of this publication may be photocopied without permission from the publisher provided that copies are distributed without charge and that full source citation is provided. The Population Council Kenya would appreciate receiving a copy of any materials in which the text is used. 


\section{Table of Contents}

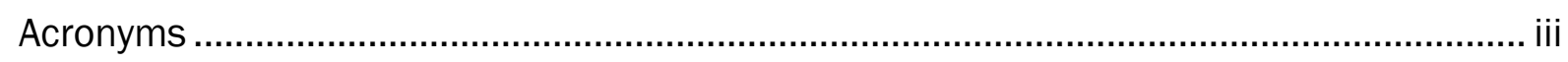

Executive Summary .................................................................................................. iv

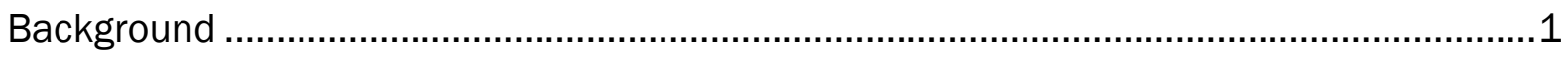

Aim

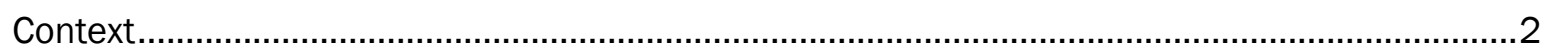

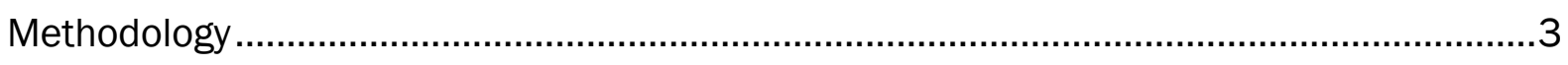

Findings

Understanding the current problems...........................................................................

Emerging Problems in the Context of COVID-19 …………………………………......

School Reopening and Safety ……………………..................................... 5

Mental health concerns.............................................................................. 6

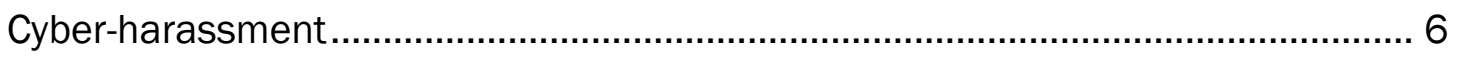

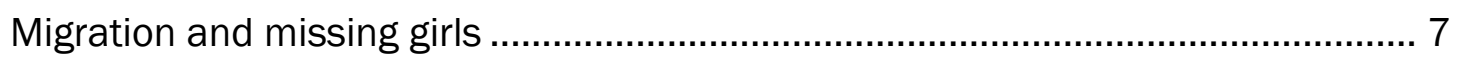

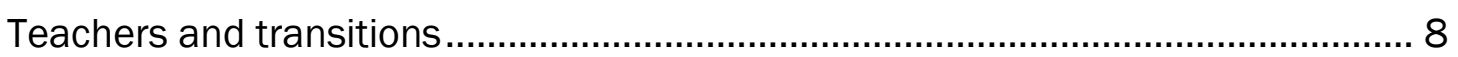

Pre-Existing Problems Exacerbated by COVID-19 ………………………………….....

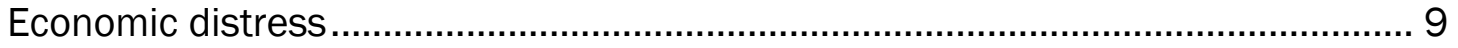

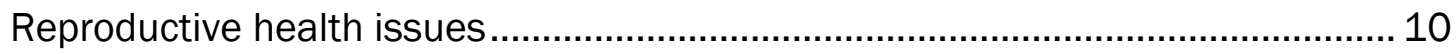

Gender-based violence ............................................................................. 10

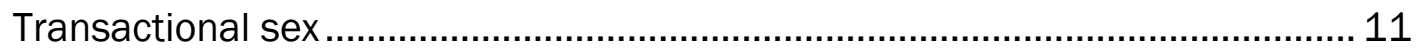

Early pregnancy ........................................................................................ 12

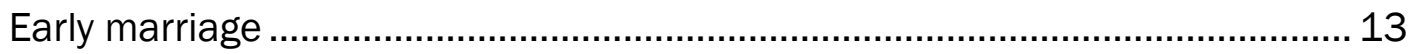

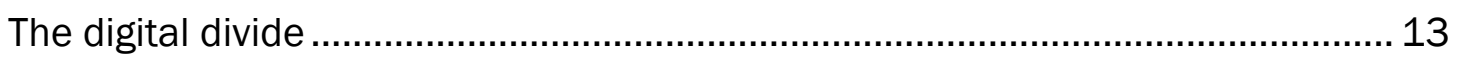

Identifying gaps in our understanding .......................................................................... 15

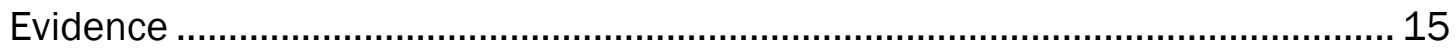

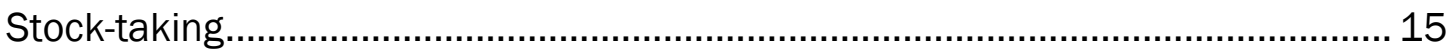

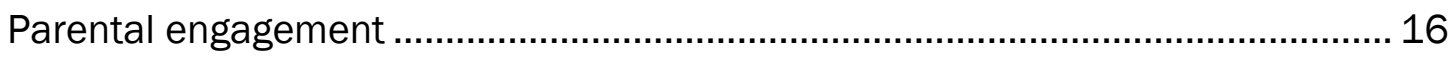

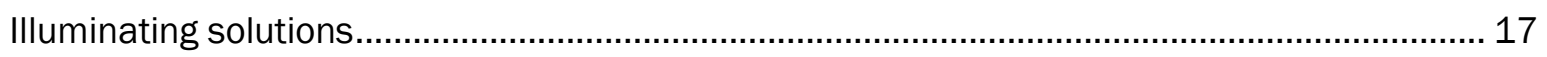

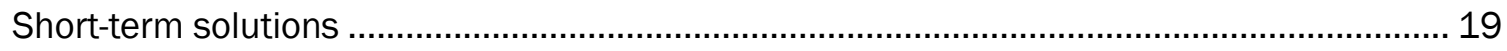

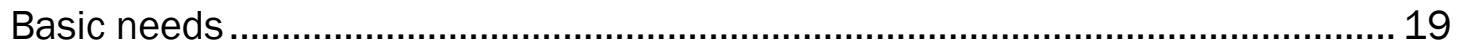

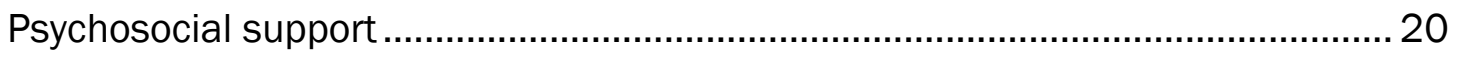

Keeping children engaged in learning during school closure............................... 20

Longer-term solutions ................................................................................................... 21

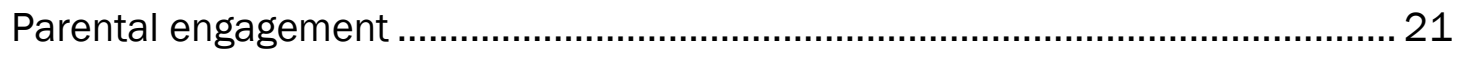

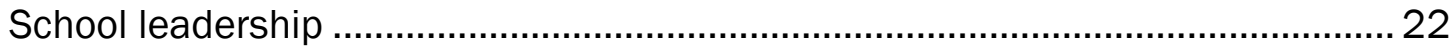

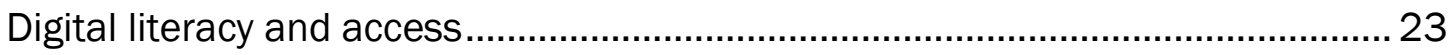




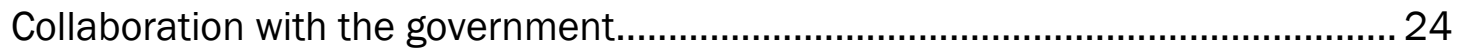

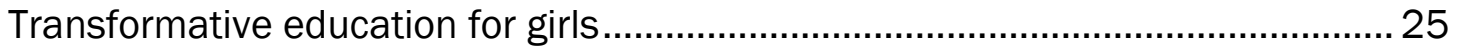

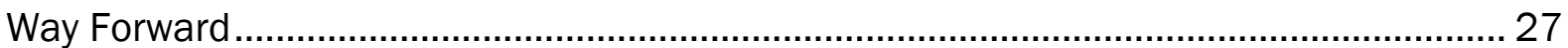

Bibliography.................................................................. Error! Bookmark not defined.

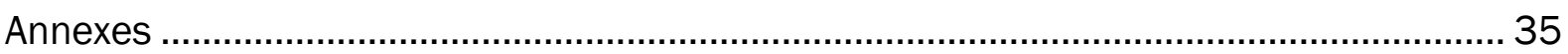

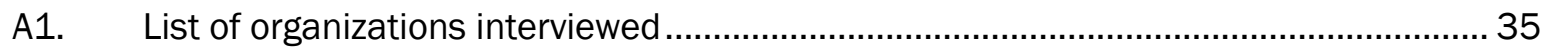

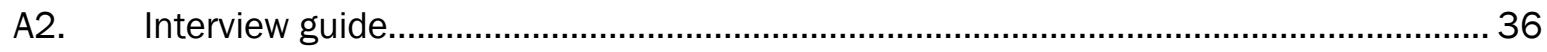

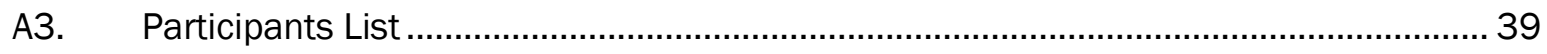

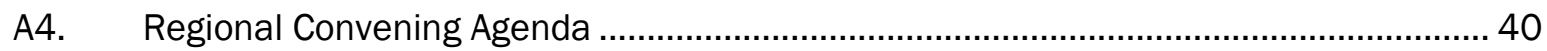




\section{Acronyms}

$\begin{array}{ll}\text { CHW } & \text { Community Health Worker } \\ \text { COVID-19 } & \text { Coronavirus Disease 2019 } \\ \text { CSO } & \text { Civil Society Organization } \\ \text { DEO } & \text { District Education Officer } \\ \text { FGM } & \text { Female Genital Mutilation } \\ \text { GBV } & \text { Gender-Based Violence } \\ \text { KII } & \text { Key Informant Interview } \\ \text { MoE } & \text { Ministry of Education } \\ \text { NGO } & \text { Non-Governmental Organization } \\ \text { PWC } & \text { Pastoral Women's Council } \\ \text { RELI } & \text { Regional Education Learning Initiative } \\ \text { STD } & \text { Sexually-Transmitted Disease } \\ \text { WASH } & \text { Water, Sanitation, and Hygiene }\end{array}$




\section{Executive Summary}

Over a billion students around the world have been affected by school closures in the past year and a half (March 2020 to August 2021) due to the COVID-19 pandemic. The persistence of the pandemic and the severity of the risks posed by the disruption of education necessitate a strong understanding of the present state of girls' education in East Africa. This study aimed to understand the current problems posed by COVID-19 for girls' education in Kenya, Tanzania, and Uganda; identify the gaps in understanding with regard to these problems; and illuminate solutions.

The study is based on a rapid desk review of peer-review and grey literature, coupled with nearly 30 key informant interviews with a range of East African organizations working on education and/or gender issues. These methods were complemented by an interactive, participatory workshop during which interviewees and other education stakeholders validated and supplemented the initial study results. Key findings from the study are summarized below.

\section{Understanding the Current Problems}

Girls' education is confronting novel problems as a consequence of the pandemic, including: mental health issues faced by girls and teachers, stemming from lockdown situations; cyber-harassment of girls in the context of increased digital learning; a crisis of well-being among girls, teachers, school leaders, due to concern about schools' ability to protect the health and safety of staff in pandemic times; and girls and teachers alike simply not returning to school as a result of permanent (private) school shutdowns, migration during prolonged school closures, and distraction by income-generating activities that were initiated to cope with economic constraints during COVID-19. Pandemic conditions have also exacerbated pre-existing problems related to girls' education, including economic distress; reproductive health issues (gender-based violence, transactional sex, early pregnancy, early marriage); and the digital divide.

\section{Identifying Gaps in Our Understanding}

In the context of COVID-19, there are gaps in concrete, robust evidence on a range of issues, including girls' school re-enrollment; reasons for dropout; learning loss; actual rates of pregnancy and other reproductive health concerns; and knowledge about effective means of engaging parents in children's home-based learning. Given the urgency and distraction of responding to the pandemic, there are few opportunities for the education sector to take stock of the important lessons learned so far during the pandemic. This gap needs to be addressed in order to ensure preparedness for future crises.

\section{Illuminating Solutions}

The following solutions are proposed for supporting girls' education in the immediate term in the time of COVID-19: Attend to girls' basic needs and psychosocial support requirements, while keeping them engaged in learning despite school closures. Longerterm solutions include bolstering parental engagement in girls' learning; engaging school leadership, given their role in determining how schools work; accelerating the digitalization of education, while simultaneously narrowing the acknowledged digital divide; fostering government-NGO collaborations for greater impact; and initiating a process that would lead to transformative education for girls, thus modifying the 
education system in ways that would mitigate the girls' education problems revealed by COVID-19.

With the advent of COVID-19 in March 2020, education stakeholders in the East African region attended rapidly to anticipated issues in the education sector, including through the development of response plans to ensure that gains made in girls' education were maintained, and that potential emerging challenges were proactively resolved. Education response plans were necessarily illustrative in the context of this unprecedented pandemic. A year and a half into the pandemic, evidence on the state of girls' education has accumulated, and the East African region is at an opportune place and time to review education sector responses in the region in light of emerging evidence. Findings from the present study can be used as a starting point for informing the adaptation and implementation of education sector COVID-19 responses in the region. 


\section{Background}

COVID-19 has appropriately been associated with novelty, uncertainty, and disruption, not least in the education sector. Within the same 10-day period from March 15 to March 24, 2020, schools were closed down in $70 \%$ of countries, globally. Over time, more than $90 \%$ of countries worldwide shut down schools in an effort to curb the transmission of COVID-19. Consequently, more than a billion students around the world have been affected by school closures in the past year and a half [i.e., March 2020 to August 2021] (Insights for Education 2021, UNESCO 2021).

Theorization around the impacts of school closures on girls' education began early on during the COVID-19 pandemic. For example, based on experiences with previous crises such as Ebola in West Africa, the Malala Fund (2020) estimated that approximately 20 million more secondary school-aged girls may never go back to school following the current pandemic. Rafaeli and Hutchison (2020) drew on evidence to surmise that women and girls in sub-Saharan Africa would suffer from extreme and multifaceted, negative, secondary impacts due to the COVID-19 crisis, including: higher poverty rates; an increase in unplanned pregnancies; a surge in school dropout rates and child labor among adolescent girls; loss of income and reduced financial empowerment; an increase in abuse and harmful practices; increased household work; reduced access to healthcare and WASH (Water, Sanitation, and Hygiene) alongside increased maternal deaths; and greater food insecurity and malnutrition. Donor organizations, such as Echidna Giving (2021), made similar early predictions about the risks the pandemic would pose for girls' education, in addition to other conjectures, such as learning loss; early marriage and/or pregnancy, and particular hardships and trauma for girls, including physical and sexual abuse, and increased female genital mutilation (FGM).

Just how severe these worrisome risks are, or are likely to be, is a challenge to determine. As schools have begun to re-open in the East African region, there is an urgent need to move beyond theorization alone to gain a better grasp on the reality of the state of girls' education in this context. This is particularly the case given the lengthy persistence of the pandemic.

\section{AIM}

The present study therefore aimed to:

1. Understand the current problems (Crowdsource from the on-the-ground experiences of organizations and research they have conducted or are aware of, to collectively come to a better understanding of the current situation for girls' education);

2. Identify gaps in our understanding (Are there high priority questions we still need to answer in order to inform a response for girls' education? What data are needed?); and

3. Illuminate solutions (How can we address the problems in order to accelerate girls' re-entry into school and ensure a quality learning experience?) 


\section{CONTEXT}

The study is situated in East Africa, with a focus on Kenya, Tanzania, and Uganda. East Africa is a particularly interesting context for exploring the issues at hand due to the rapid response of non-governmental organizations (NGOs) in the region upon the advent of COVID-19. These NGOs worked quickly (and collaboratively) to adapt their operating models while schools were closed. Many organizations developed remote learning support for students. Others pursued their existing work with increased urgency, innovation, and more strategic approaches.

Over the course of the pandemic, the East Africa-based Regional Education Learning Initiative (RELI) has remained active. RELI is both a peer learning initiative and policyinfluencing network that seeks to realize equitable, quality education for all children across East Africa. Member organizations have continued to share evidence and intelligence to help one another adapt to the quickly-evolving crisis. They have also collectively and strategically engaged with policymakers. Furthermore, schools in the region are at different stages of the re-opening process: Kenya's school closure had a duration of about 9 months, with schools recently reopening. Uganda has had the longest school closure period of more than a year. Although school reopening in this context initially occurred in a phased manner as from early 2021, a new phase of school closure began in June 2021. In contrast to the long period of school closures in Kenya and Uganda, schools in Tanzania had a relatively shorter period of school closure (under 4 months).

Each country also has its individual policy approach to supporting retention within, and re-entry into, schools for vulnerable girls. Kenya's school re-entry policy implementation guidelines (Kenya MoE, 2020) are designed to support all out-of-school children, regardless of gender, and its national school health policy (Kenya MOPHS, 2009; Kenya $\mathrm{MoE} \& \mathrm{MoH}, 2018$ ) specifically supports retention for pregnant learners. In Tanzania, pregnant girls are expelled from school, and there is currently no policy or clear system in place for pregnant and parenting girls to re-enter the formal education system. In Uganda, where the school re-entry policy has been in draft form for several years, the guidelines for the prevention and management of teenage pregnancy in school settings were revised during the pandemic in response to concerns around elevated rates of teenage pregnancy in the context of COVID-19. The revised guidelines permit pregnant and parenting girls to re-enter school (Uganda MOES, 2020).

These varied contexts provided an opportunity to learn from East African country settings at different stages and with different experiences, while also engaging interested members of the RELI network and a wider group of gender and education experts from the region in an explicit conversation about girls' education. 

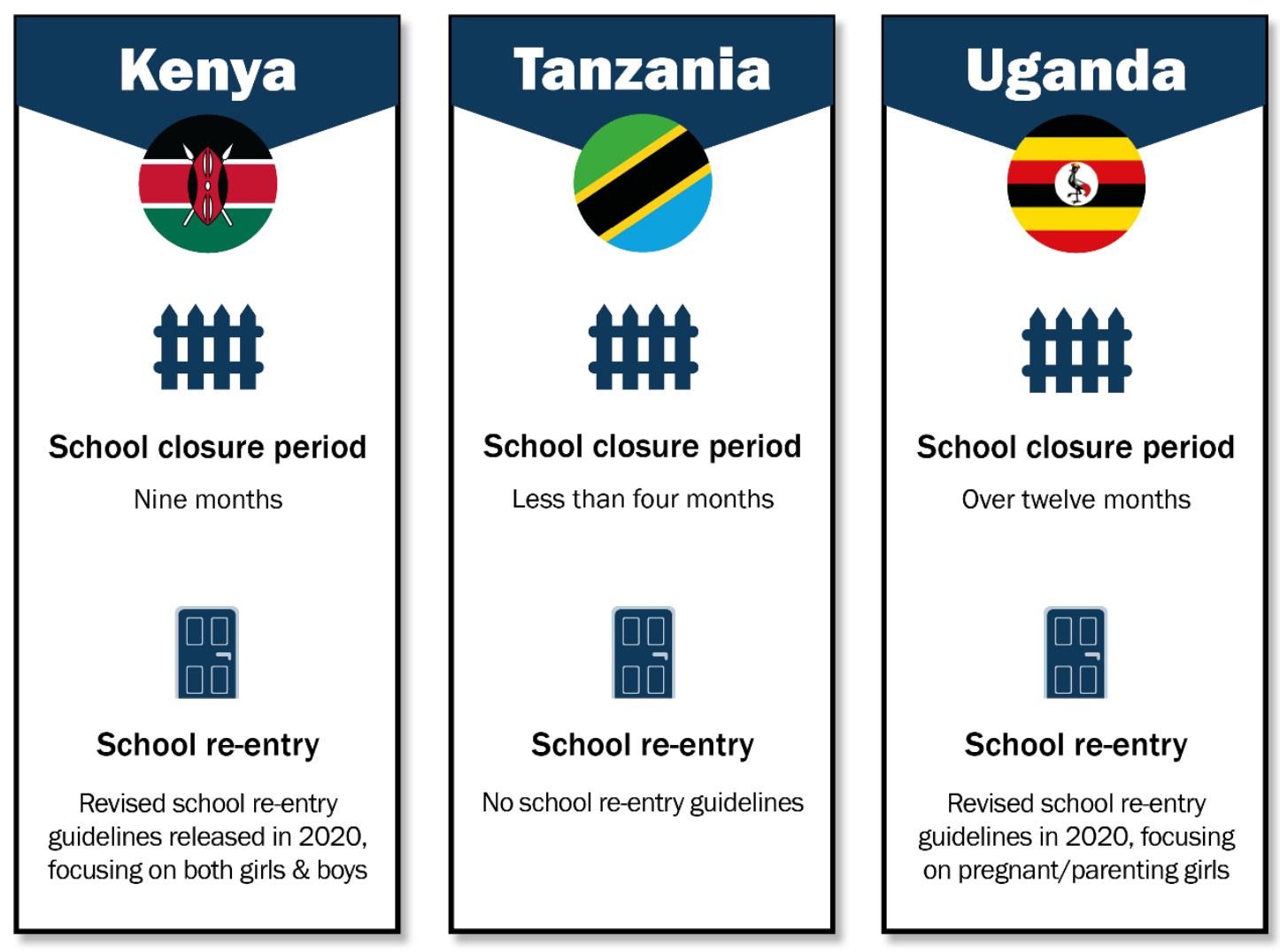

\section{Methodology}

COVID-19 and its effects on education are a rapidly emerging narrative. Priorities in this area have already begun to surface, and continue to be fast-moving, with a need for 'realtime' data. In recognition of these realities, the study involved a rapid desk review, coupled with key informant interviews (KIIs).

The rapid desk review focused on emerging peer-review and grey literature available electronically and centered on the study's focal areas of understanding the current problems in girls' education during COVID-19, identifying the gaps in understanding, and illuminating solutions in East Africa. Publications by the organizations invited to participate in the KIIs were also identified as part of the KII process. Such publications were sometimes in progress or unpublished, but where still included, where allowed by the organizations concerned.

A total of thirty (30) key informants were selected from a range of organizations $(n=29)$ across the East African region working on education and/or gender issues. The majority of the key informants were drawn from RELI member organizations with work that 
focused on the intersection of girls' education and COVID-19. Other selection criteria included: geographical focus of the organizations (Kenya, Tanzania, Uganda, or 'Regional' - i.e., in more than one of these countries), subject areas of expertise (education, gender, violence, human rights), and approach (research, community-based service delivery, advocacy, policy). The variation among the selected organizations was geared toward ensuring the richness of perspective and experience, as well as a comprehensive understanding of the issues at hand.

Of the 29 organizations invited to participate in the KIIs, 27 completed the interviews (see Annex A1). Together, these organizations represent tens of thousands of children and families in the East African region, in terms of the reach of their programming and/or research. The interviews, which averaged about an hour in length, were facilitated by a semi-structured field guide (see Annex A2) and took place via Zoom. The KIls were audiorecorded with the consent of the interviewees. After each interview, interview summary notes were developed and shared with respondents for review and confirmation that the key points of their individual interviews had been captured.

The information obtained from the rapid desk review and KII summary notes were coded according to the three key domains explored by the study, namely: understanding the current problems, identifying gaps in our understanding, and illuminating solutions. Each domain was then explored further through continued review of coded chunks of text from all interviews within and across countries to distill smaller pockets of meaning (subthemes) embedded within the key domains. New codes that emerged during the analysis were also incorporated into the coding scheme. The study findings are presented in this report according to the key and emerging domains.

Prior to the publication of the report, the findings were disseminated to a group of nearly 50 education stakeholders (study interviewees, other education organization representatives from the East African region and beyond, and donor organizations - see Annex A3) during an interactive, participatory virtual convening that took place from June 12-13, 2021 (see Annex A4). The convening was designed to obtain feedback from participants on the accuracy of the findings, as well as on any missing information that was key for understanding the current realities of girls' education in the time of COVID19. The meeting also served as a platform for co-creating solutions to the emerging problems. Participants were provided with the draft report and had a week after the convening to provide any comments prior to the finalization of the document. The 'Next Steps' section of the draft was deliberately left unwritten to ensure that discussions and conclusions from the convening informed the way forward. Accordingly, narratives from the convening's interactive discussions were documented by facilitators in real-time, organized into themes, and are presented in summary form the 'Way Forward' section. 


\section{Findings}

\section{UNDERSTANDING THE CURRENT PROBLEMS}

As the majority of respondents emphasized, the problems within girls' education in East Africa in the time of COVID-19 operate along a continuum, posing challenges for disentangling 'old' problems from 'new' predicaments. In the words of one key informant:

The classification of 'brand new' problems versus 'pre-existing' problems is not a helpful lens to look at [girls' education with]. Many people .... would rather want to come with a lens of a brand new problem, but we should look at it along a continuum. At some stage, [a particular problem] was reduced, and then, with COVID-19, it was exacerbated. ... What we should not do is to look for new problems. The issues of girls' education [that] we would find [are] exacerbated issues ... and not [necessarily] new issues (Key informant, Kenya, May 2021).

Nonetheless, to showcase where various problems are located along the acknowledged continuum, this section first presents 'novel' problems that largely stem from 'old' challenges, but that manifest in new ways as a consequence of COVID. It then delves into problems that clearly pre-date COVID-19, but that are still important to highlight due to the ways in which they have been exacerbated by the pandemic.

\section{Emerging Problems in the Context of COVID-19}

\section{School Reopening and Safety}

After a period of school closure, schools faced new challenges associated with reopening. The majority of schools were already characterized by inadequate facilities, including overcrowded classrooms and the lack of WASH resources. Such schools were obligated to adhere to COVID-19 prevention measures, nonetheless, and this posed additional challenges and concerns. The lack of essential facilities and resources disincentivized students' return to school. This was coupled with a crisis of well-being among teachers and school leaders, who were anxious about their own safety, as well. School personnel lacked psychosocial support for coping with their anxiety about schools reopening in the midst of the pandemic, and the trauma caused by COVID-19 in general.

There is fear of COVID-19, and they [school personnel] also need to follow the Standard Operating Procedures issued by the government regarding COVID (Key informant, Uganda, May 2021).

The learning environment is challenging. There is no soap, sanitizers, menstrual health products (Key informant, Tanzania, June 2021).

One of the new problems that emerged was the crisis of well-being amongst teachers and school leaders. Are we safe at school? Nobody is helping teachers cope with anxiety and trauma caused by the pandemic and provide psychosocial support. There are many 
health and safety issues on how to keep children and teachers safe at school (Key informant, Kenya, May 2021).

\section{Mental health concerns}

The study findings indicate that mental health-related issues are not the preserve of school personnel alone. The mental health issues confronted by girls was a recurrent theme among many respondents who highlighted girls' waning levels of hope and motivation with regard to continuing their education; the stress of having to cope with an accelerated syllabus (to make up for lost time); and trauma experienced by some girls who were subjected to gender-based violence or experienced pregnancy during school closure periods. As several key informants opined:

It has been a challenge because of the uncertainties, the new reality. Students are home all the time, and they don't know if they are going back. Also, when they go back to school, it is like a stressful crash course to cover the syllabus. Counseling from teachers at school is not $100 \%$ the way it should be, but it's a step towards the right direction (Key informant, Kenya, May 2021).

Most of the girls have lost their esteem. They are vulnerable (Key informant, Uganda, May 2021).

Even before the pandemic, the psychosocial element was a big issue in our program in the urban informal settlement, and the pandemic seems to have made a significant impact on the adolescents through the parents losing jobs, the restrictions they went through, and the uncertainty of the situation by the pandemic. The pandemic has been a stressor. The impact of pandemic on their psychosocial well-being may never be quantified, but the fear is that it may have a long-term effect on these youths in their later adulthood (Key informant, Regional, May 2021).

The concerns and stress of students were also observed, for example, during the initial re-opening of the schools in Kenya in early 2021, through student riots and school arson attacks carried out by students. Even in Tanzania, where the school closure period was much shorter than Uganda and Kenya, key informants pointed out that its impact was evident upon reopening, as schools continue to struggle to bring girls back, and linkages were made between school closure and the traumatization of girls: "Every week that schools were closed, it counted, and it was detrimental to the students, especially the girls' (Key informant, Tanzania, June 2021).

\section{Cyber-harassment}

The closure of physical school spaces in the region as a consequence of COVID-19 often meant that virtual schooling became the new means of accessing learning. This shift came with consequences of its own for girls, including exposure to cyber-harassment via the new, digital platforms employed for learning. Some respondents noted that the swift, mass move to digital platforms during the pandemic was often not accompanied by education around the necessary precautions to take when using online learning formats. The latter provided opportunities for online predators to target and take advantage of girls engaged in learning: 
[K]ids ... become targets of predators. Some [predators] are shooting child pornography, and other strange things [are] going on. When kids are left with a lot of time and are unsupervised, unprotected, they often become vulnerable (Key informant, Regional. May 2021).

Furthermore, gaining access to devices to facilitate access to online learning platforms came with risks. Some girls who attempted to borrow smart phones and other devices ended up being asked for sexual favors in return. These realities, coupled with the fact that school closures often left children at home without adult supervision, led to heightened concern among key informants that girls were being exposed to harmful information, activities, and people, both virtually and in person:

We availed a smart phone to effectively run the program. This was because family members and predators had started using smart phone access as bait to lure girls into sexual exploitation (Key informant, Kenya, June 2021).

\section{Migration and missing girls}

In non-pandemic times, school closure in the East African region is typically followed by migration at different levels (urban-rural, rural-urban, urban-urban, rural-rural), as students return from their school locations to their homes. This norm was maintained when the COVID-19 pandemic hit. However, the lockdown and curfew stipulations accompanying the pandemic introduced new dynamics to this norm: It posed challenges for education organizations to keep track of some children within their programs (who did not return upon the reopening of schools) and gain a sense of what was occurring in their lives. Exacerbating this issue was the fact that schools themselves, and parents, faced financial challenges. Many private and community-based schools grappled with having to close down, as families were no longer able to make school fee payments. Some students at such schools had no other schooling alternatives. Others moved to public schools - already overstretched by student enrollment prior to the pandemic.

We are tracking the girls' re-enrolment with our school partners. Public schools are reporting pretty good re-enrollment (around $80-90 \%$ ). Community schools: $50-60 \%$ reenrollment. Families' economic situation has been affected. There might be some movement between private and public [schools] that might have affected the data. There is no data available, so it's really hard to say. The common barriers: got married, got pregnant during COVID, child labor. If they started working during in the pandemic, it is a shift of mindset and a practicality issue of whether they can afford to lose their income. There are some girls that have been providers for their families either because of loss of parents or a shift in the family dynamics. School might not seem like an option (Key informant, Kenya, May 2021).

The girls are back at home. Normally, even pre-COVID, when girls are going back home for longer breaks, there are many issues. When the schools closed, there was that feeling that the girls will not be safe at home over a long period of time. It was really hard to reach the girls. After a month, we conducted a survey and found out that most of the girls in our programs were now involved in economic activities instead of [at] home (Key informant, Tanzania, May 2021). 
We were surprised that so many girls were not coming back to school. ... some girls were married and others, pregnant. ... In four of the secondary schools we work with, 55\% of girls did not come back to school. One of the primary schools we work with said that more than $60 \%$ of girls have not come back to school after reopening (Key informant, Uganda, May 2021).

The study's key informant interview and rapid desk review data align on the issue of missing girls. For instance, a Kenya-based cohort study indicates that girls were twice as likely as boys to not return to school during the pandemic: About $16 \%$ of girls enrolled in school in March 2020 did not re-enroll in February 2021, compared to about 8\% of boys (Kenya Executive Office of the President \& Population Council, 2021). Those that did not return to school (about a quarter of a million girls and 120,000 boys) were almost exclusively aged 15 to 19, while almost all younger adolescents went back to school. This is not unexpected in Kenya, where costs associated with primary school education are much lower than those related to secondary school education. A study in the Ugandan context, based on 27 public and government-aided secondary schools, demonstrates that the average school-returning rate was $85 \%$ for boys and $80 \%$ for girls as of November 2020 (ISER 2020).

\section{Teachers and transitions}

The economic downturn characterizing the COVID-19 pandemic in East Africa had an adverse effect on teachers, as well. Respondents noted that many schools faced a high rate of teacher attrition. Many teachers (in private and community-based schools, particularly) were not paid during the school closure periods and were therefore obligated to find new ways to make a living. Interviewees pointed out that some teachers opted not to return after the school re-opening, leading to a loss of some of the most capable instructors. The pandemic created (or reinforced) the notion that the teaching profession is an unstable one, leading some teachers to pursue other professions.

Many teachers who were good have found other jobs and have not come back to school (Key informant, Uganda, June 2021).

When they closed the schools, school leaders and teachers did not receive funding from families, so there was a big teacher turnover as they left to find other ways to sustain themselves. ... The teacher turnover [in community schools] was about 60 to 70 percent. ... [T] eachers during COVID-19 realized that being a teacher in a community school is not very stable (Key informant, Kenya, May 2021).

\section{Pre-Existing Problems Exacerbated by COVID-19}

Nearly all key informants asserted that COVID-19 'exacerbated' pre-existing problems: While the problems concerned existed prior to the pandemic, COVID-19 unmasked them further, lending a clearer understanding of their magnitude, intensity, and urgency.

The key informant interviews helped establish a multi-dimensional pathway of how the pandemic is affecting girls' education in the region (Figure 2). This pathway is populated 
by a range of barriers, broadly including economic distress, reproductive health issues, and the digital divide. In the following sub-sections, we explore each of these barriers in further detail.

\section{Figure 2: COVID-19 exacerbated pre-existing problems}

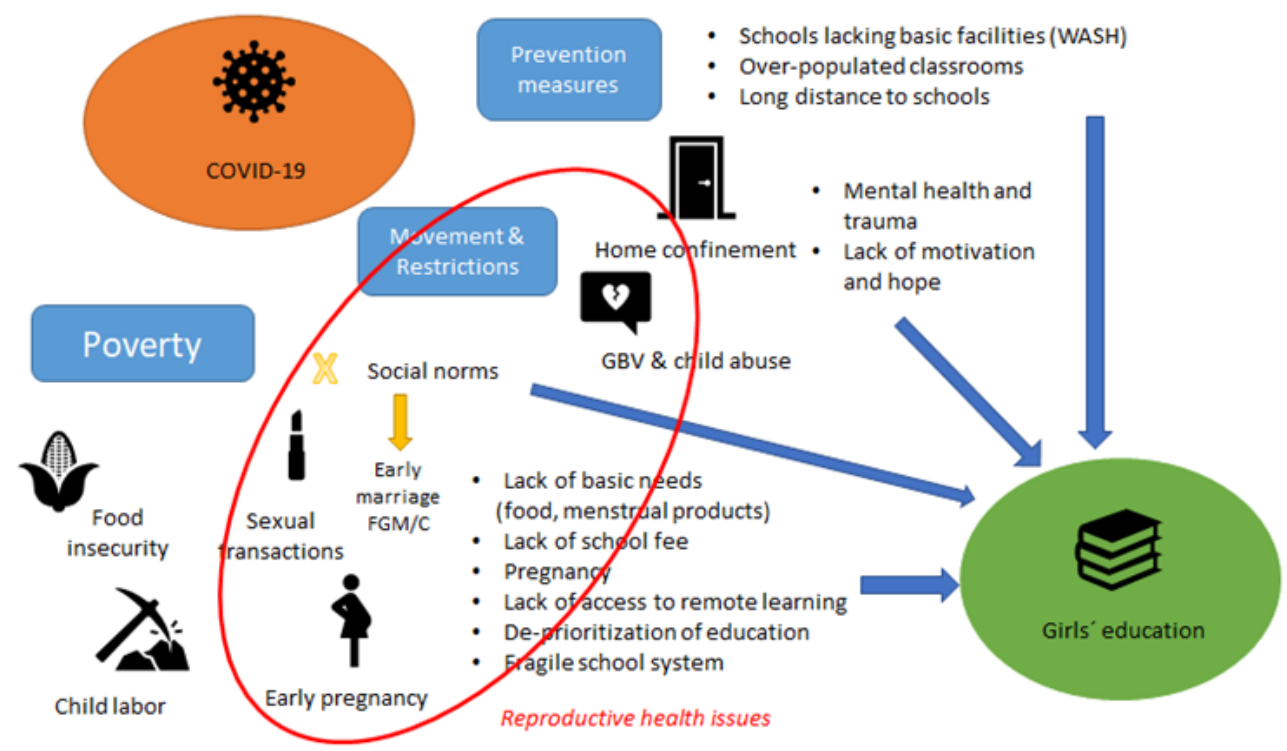

\section{Economic distress}

Key informants described the economic distress caused by COVID-19 as having had a significant impact on families and children, leading to food insecurity and a lack of resources to cope with the range of challenges faced by families. Consequently, many girls were forced to contribute to household income through child labor outside the home, or to handle tasks such as household chores and caring for family members. In terms of priorities, girls' education paled in comparison to these responsibilities. Due to entrenched gender norms, particularly in rural regions, the education of sons was often prioritized over that of daughters: 'Parents were asking girls not to study much, and to be flexible - which makes sense if the parents lost their jobs and needed support in selling their vegetables' (Key informant, gender, Kenya, June 2021).

As many respondents observed, justifying girls' continued education after schools reopened became difficult for some families (and for girls themselves) who had become accustomed to the income being generated by girls: 'The circumstances forced them there, but they need the money. It was a blessing in disguise because they can now get what they need. If I leave work, how would my parents survive?' (Key informant, Uganda, June 2021). Furthermore, some interviewees pointed out that school completion does not necessarily guarantee employment in their contexts, and that many schools already struggle to provide adequate facilities and quality education for their students. 
Emerging literature corroborates these findings. A study of COVID-19 implications for household income and food security in Kenya and Uganda showed evidence of worsening food security in the two countries. This was attributed to income loss or reduction, reduced access to markets due to travel restrictions, and low purchasing power (Kansiime et al., 2021). Across the study countries, the number of food-insecure respondents increased by $38 \%$ and $44 \%$ in Kenya and Uganda, respectively. Food security outcomes were found to be worse among the income-poor and those dependent on labor income, as they were less likely to have adequate savings for food purchase amidst increased food prices. The ICRW Africa Hub conducted a landscape analysis of the policies enacted from March 2020 to January 2021 in response to COVID-19. Their conclusion was that the informal sector - one dominated by women - clearly did not benefit from the economic stimulus packages in Kenya and Uganda (ICRW, 2020).

Research conducted in Kenya also found that households experienced extreme economic shocks (85\% and $75 \%$ of respondents in urban and rural areas, respectively, lost income), leading to household food insecurity, lack of access to healthcare, and other challenges (Population Council, forthcoming). In a broader, Kenya-based cohort study, 'school fees' was observed as being the top reason why about $50 \%$ of students (both girls and boys) were not returning to school. The second reason for boys was 'started to work' (Kenya Executive Office of the President \& Population Council, 2021).

\section{Reproductive health issues}

\section{Gender-based violence}

The rapid desk review data painted a bleak portrait of the impact of COVID-19 on girls' exposure to sexual violence, in particular. Emerging evidence from Kenya suggests that the lockdowns and school closures associated with the pandemic provided further opportunities for children to be violated at younger ages in private residences by individuals known to them (Stevens et al., 2021). Children, particularly girls, were noted as having heightened vulnerability to sexual violence committed by non-stranger perpetrators (e.g., neighbors) in the daytime (ibid.). Indeed, vulnerability to violence has been observed as having amplified across populations in general, according to reports from human rights actors (Flowe et al., 2020). Uganda presents a similar situation, with a noted rise in the incidence of child sexual and physical abuse (along with child labor) since the implementation of COVID-19 lockdown measures (Sserwanja et al., 2021).

These accounts, and the urgency of the issue of gender-based violence (GBV) were corroborated by key informants directly working on, or familiar with, GBV in the region. Notably, even organizations with vast GBV experience were blindsided by the levels of sexual violence and rape-related pregnancy observed in their programs during COVID-19. Incest, in particular, was highlighted as a serious problem which was perceived to have escalated under lockdown situations, and some organizations were grappling with how to empower children with information on how to get help when faced with this issue: 
Most challenging issue has been how to address incest as a form of sexual violence. The perpetrators are relatives or people within their homes. How do you report and take to court your father or some other close family member? How do you protect yourself and your family? (Key informant, Uganda, June 2021)

As one respondent pointed out: 'GBV has been regarded as a 'health' issue, but the pandemic made it clear that it is also [about] 'economic' and 'social' issues' (Key informant, Regional, May 2021).

"Given the lockdown, we expected the parents to be more supportive and protective of their children. If we have cases of pregnancy and incest instead, you wonder what the parents were doing with their children instead of building their family value of care and love, not of violence. Often the parents take their children to school for them to learn and grow. But if the same parents expose their children to violence, you wonder what is the role of the parents? If they are having sex with their children, why do they care about their children graduating and education?

The economic hardship is no excuse for the parents to be violent with their children or cause harm and pain to the children. Abuser is an abuser. Moral decadence is unacceptable. Everyone struggled, but the abuse remains unacceptable."

Monica Nyiraguhabwa, Girl Up Initiative Uganda A gender-equal world where girls thrive and lead

\section{Transactional sex}

The economic distress brought on by the pandemic led to the reliance of many girls on sexual transactions, when they could no longer meet their basic needs (e.g., food, menstrual products):

Our partners had to step in and provide food and money and basic menstrual hygiene products, including sanitary pads. That's because many girls were exchanging sex to access sanitary pads, and this resulted in teenage pregnancies (Key informant, Regional, May 2021).

Boys and, especially, girls, they lack resources and exchange what is needed for sexual favors - for example, menstrual pads (Key informant, Kenya, May 2021).

While transactional sex among girls pre-dated the pandemic, COVID-19 was noted as having increased dependence on such transactions. A Nairobi-based study, for instance, indicated that $49 \%$ of young women reported increased dependence on transactional sex during the pandemic period (PMA Agile/Gender \& ICRHK 2020). On the other hand, some girls turned to transactional sex simply because they felt vulnerable and uncertain about the future under the circumstances imposed by COVID-19 (PMA Agile/Gender \& ICRHK 2020). 
Schools that provided healthcare to students saw a rise in sexually-transmitted infections among girls who returned to school: 'We've noticed an increase of STDs (sexuallytransmitted diseases) because girls became sexually active [during the pandemic]' (Key informant, Kenya, June 2021).

\section{Early pregnancy}

Early pregnancy was an issue raised by most key informants during the KIIs on COVID-19 and girls' education. However, comprehensive and reliable data on early pregnancy were difficult to find via the rapid desk review. Much of the reporting on early pregnancy in the East African region was noted as being media-based, and focused on program (rather than population-based) contexts, or centered on the number of early pregnancies without referring to the rates or comparisons with previous years. Although some organizations that participated in the current study are carrying out research on this subject, it was still too early (at the time of this study) for most of them to be able to obtain rigorous data on early pregnancy in the context of COVID-19.

Nonetheless, there was a strong perception among some organizations that an increase in early pregnancy had been stimulated during the COVID-19 pandemic, which forced girls to remain at home, and which also increased girls' vulnerability to sexual violence. For example, a girls-only boarding school in Kenya that caters to girls from low-income households maintained a pregnancy rate of 1 out of every 100 girls prior to the pandemic. However, upon schools reopening in 2021, 6 out of 100 girls were pregnant for the first time ever, leading one key informant to the conclusion that: 'Schools are the best contraceptives' (Key informant, Kenya, May 2021).

A study in Uganda also reported an increase in early pregnancy during COVID:

Between March 2020 and June 2020, there was a 22.5\% increase in pregnancy among girls aged 10-24 seeking first antenatal care. Among girls aged 10-14 years, incidence of pregnancies had increased the most (by a staggering 366.5 percent-from 290 in March to 1,353 in September, 2020) compared to those aged 15-19 years (25.5\%) and young women aged 20-24 (21.1\%) (FAWE Uganda, 2021).

Nevertheless, key informants from the research community emphasized the need to be cautious in coming to conclusions about increases in early pregnancy rates at this stage, particularly as such rates have tended to be high in the absence of the pandemic: "We need to still wait and see the longer-term effect of the pandemic on teenage pregnancy and how girls' education was affected by the pandemic' (Key informant, Kenya, May 2021).

Some of the same respondents, however, pointed out that the pandemic has drawn heightened attention to the issue of early pregnancy, due to the strong perception of high rates during COVID. This was observed as being advantageous for spurring action toward hopefully resolving an 'old' problem that has historically been fraught with taboos. 


\section{Early marriage}

A few organizations mentioned losing girls in their programs to early marriage during school closure periods. Organizations that worked to rescue girls from early marriage were faced with challenges during lockdown and curfew situations, which inhibited their ability to establish contact with at-risk girls and physically rescue them. Oftentimes, marriage decisions had already been made by the time such organizations managed to visit at-risk girls and their families and intervene at the household level.

Early marriage was described by respondents as an income generation avenue for economically constrained families, given the dowry payments associated with it, and the fact that it resulted in one less mouth to feed within the household during economicallyconstrained pandemic times. Extended school closures in the context of lockdowns presented an opportunity for girls to undergo marriage preparations (including FGM) with less likelihood of external interference from government and civil society organizations.

Girls were noted as sometimes exercising agency in these decisions to get married early. In such cases, the girls concerned, according to respondents, typically struggled with their school performance prior to school closures, and therefore viewed marriage as a viable option. A key informant described a recent experience during a household visit to a girl who had made such a decision: 'The girl's home was headed by a single mother. We went to speak with her. We were saddened by the lack of support from the parent. The mother just said, 'Let her go. She does not want to go back to school' (Key informant, Kenya, May 2021).

\section{The digital divide}

The COVID-19 pandemic highlighted the undeniable and worrisome digital divide experienced by children and their families across the East African region. Key informants in Kenya, Tanzania, and Uganda alike emphasized the gap between children's educational experiences during the pandemic, informed by their families' socioeconomic statuses. A Kenya-based study situated in 42 out of the country's 47 counties, drew on interviews about children's digital learning with 3,735 households (representing over 10,000 school-going children, spanning all pre-school, primary, and secondary school classes) and nearly 300 county and sub-county chairpersons of Kenya Primary School

Heads Associations and Kenya Secondary School Heads Associations from all counties (Uwezo, 2020). This study found that: 1) access to digital learning was low and inequitable; 2) parental awareness about children's remote learning was disparate; 3) the most utilized platforms for accessing digital learning (e.g., WhatsApp, television) were not the most accessible; and 4) public schools were the least prepared (compared to private schools) to support digital learning. On average, 22 out of 100 children who attended either public or private schools were accessing digital learning; 42 out of 100 digital learners accessed TV lessons; 27 out of 100 digital learners accessed materials sent by schools via WhatsApp; and 10 out of 100 digital learners accessed the Kenya Institute of Curriculum Development's digital materials designed for the pandemic period. 
As a key informant explained:

The challenge after COVID-19 is how to bring back those who were really pushed to the edge by the pandemic, to where the others are. We found in the remote learning survey that the children whose social-economic status was the lowest suffered the most from [the lack of] access to remote learning (Key informant, Kenya, May 2021).

In Tanzania and Uganda, respondents intimated that many children were unable to learn at home due to the unavailability of devices to support remote learning (internet, television, radio, etc.). An assessment conducted by CAMFED in Tanzania revealed that within their program composed of over 9,000 students, only $34 \%$ of students lived in households with electricity; $21 \%$ were lived in households with a television; $38 \%$ lived in households with a radio; and $24 \%$ lived in households where at least one family member had a smartphone (CAMFED Tanzania, 2021). Students in urban areas fared better than their rural peers in terms of access to these resources. For instance, only $21 \%$ of students in rural areas lived in households with electricity, compared to $46 \%$ of their urban counterparts. This pattern was similar for households with a television $(10 \%$ of rural students compared to $31 \%$ of urban students); households with a radio (32\% of rural students, compared to $44 \%$ of their urban peers); and households with a member owning a smartphone (17\% of rural students, versus $31 \%$ of urban students) (ibid.).

For students who had the resources to participate in virtual learning, ensuring confidentiality was an issue, as noted primarily by organizations that focused on life skills education: Girls were not necessarily comfortable with receiving certain life skills education messages via a phone that they did not personally own. Respondents noted that girls' expressed fear about the recording features of smart phones, or of having others in the household listen in on their conversations, for example.

Key informants pointed out that the digital divide in the context of the pandemic is not just a socioeconomic issue - it is also an issue of different abilities and special education realities. The few organizations that specifically worked to address the education requirements of special needs children during school closures indicated that girls with special needs were overlooked during the pandemic. There was, therefore, a severe lack of resources and know-how for developing educational materials for this population. Consequently, support was restricted to certain sub-populations of learners with disabilities: 'This was an issue that was brought up and discussed in the context of the pandemic. The government supported some organizations to develop resources and materials for the visually-impaired' (Key informant, Tanzania, June 2021). Government radio and television programs were not accessible by all learners, such as the visually- or hearing-impaired. Children with special needs, thus, faced unique challenges in accessing education during school closure periods. 


\section{IDENTIFYING GAPS IN OUR UNDERSTANDING}

\section{Evidence}

Interviewees highlighted several gaps that need to be filled in order to provide a comprehensive account of the state of girls' education in East Africa in the time of COVID-19. Key among these gaps was the lack of robust evidence on a range of problems highlighted in this report, including re-enrollment, reasons for dropout, rates of pregnancy and other reproductive health concerns, learning loss, and parental engagement. These gaps in evidence at this stage of the pandemic are understandable, given the various movement restrictions in the region, which posed challenges for carrying out rigorous studies. Furthermore, in a country such as Tanzania, political decisions made by the previous government hampered data collection and research efforts. Nevertheless, organizations expressed optimism that the required data was forthcoming, with several participating organizations being in the process of carrying out studies to fill various gaps themselves. They emphasized the need for a variety of evidence sources, including comprehensive, large-scale data sets; institution-focused surveys; and routine program/administrative data.

Key informants viewed new data as not only contributing toward enhancing understanding of the issues, but also as being imperative for informing the appropriate responses in the education sector. Connected to this was an underscored need for governments to be receptive to evidence in the time of COVID-19:

We need to produce more data and evidence around the learning gap to push the education agenda. The issue is that there is still a prevailing mindset that the education system is working, so there is not an urge or drive for a change. There is alternative education and learning for students who have dropped out, but the government hasn't recognized yet that there are students that [started] school from day one, and after six years of public education, they are coming out without having had the right education (Key informant, Tanzania, June 2021).

The conversation on education has [become] more and more evidence-based, and the government needs to accept the data and the situation. More data is absolutely critical in informing the next steps and the future direction of education (Key informant, Kenya, May 2021).

\section{Stock-taking}

Another key gap that emerged in respondents' narratives had to do with taking stock of lessons learned during the pandemic so far. Many interviewees expressed concern over the urgent need for the education sector to carry out such a stock-taking exercise during the pandemic, particularly to ensure preparedness for future crises. Respondents observed that there was room for improvement in responding to crises in the future, including ensuring comprehensive input from a range of stakeholders in crafting national and education sector-specific responses: 
The President just announced school closure, but the Ministry of Education was not part of the COVID task force. If they were, they would not have sent back the kids back home this way. What does this tell us about the future of education and the society overall? (Key informant, Uganda, June 2021).

Everyone is struggling with the issue of preparedness. There may be a fourth wave, and things are evolving. What did we learn from our mistakes, and if there is another pandemic, what sort of preparedness do the communities, learners, and schools have at that point? (Key informant, community, Kenya, May 2021).

Key informants also had specific ideas for addressing future crises differently in the education sector:

When the schools were closed, there was an outcry from the girls regarding abuse, early pregnancy, early marriage ... Can the government consider such voices and not close down the schools? ... There is no strategy at this point on what to do if COVID gets worse and another lockdown is called. We would recommend [keeping] the girls in school to protect them (Key informant, Kenya, May 2021).

\section{Parental engagement}

A gap in knowledge of how to engage parents became apparent during COVID-19. PreCOVID-19, a substantial amount of the burden for girls' learning rested on schools' shoulders. However, the pandemic highlighted the key role of parents in their children's education, particularly in situations where children were obligated to engage in homebased learning. With virtual learning came the realization that schools and other stakeholders lacked the tools and know-how with which to engage with parents and support their involvement in their children's home-based education. As one respondent put it:

How do we engage the parents? ... [Parents] play such an important role in [the lives of] their children. What do the parents tell the child, what do they talk about? Do they just do homework[?] Initially, the parents refused to accept this role, saying that it is the role of the teachers, but the COVID-19 situation changed this. The parents need support to better 'teach' and 'support' their children and their learning. 'Re-parent' the parent - it is an integral part [of] education, since they are the first teachers the kids have. It'll be interesting to know more about it. That part is left out (Key informant, Kenya, May 2021).

Key informants also pointed out the urban-rural differentials in parental engagement: 'Parental engagement with their children in the rural community was low. We need to look into this and conduct research' (Key informant, Uganda, May 2021).

Related to the issue of parental engagement is the role of male parents, in particular. Respondents stressed the need to clarify and understand this role, given the pressure that lockdown learning situations placed on families in the region. While mothers have conventionally been viewed as the parent to engage in children's schooling, COVID-19 raised awareness of the need and opportunities to engage fathers, too: 
How can we encourage men to be part of this process? Strategizing used to be femalefocused, but we are leaving out [others] who should be part of the process (Key informant, Uganda, June 2021).

What is the role of men? The role of men in engaging children and learning - this is something not really addressed yet nor discussed. Most of the time, when we talk about parents, women are more available and concerned. What is keeping the men away? Are they working? What about their availability? (Key informant, Kenya, May 2021).

\section{ILLUMINATING SOLUTIONS}

Despite all the challenges created or magnified during COVID-19, participating organizations were keenly aware of the opportunities wrought by the pandemic. For instance, respondents were of the opinion that education and gender became more of a focus in the region in the context of COVI-19, and with enhanced media reporting, public awareness, and policy debate, these issues moved up on national agendas. Key informants emphasized the heightened attention that COVID-19 brought to education and gender, whether in regard to education technology, school re-entry for parenting/pregnant girls, or girls' empowerment:

COVID-19 opened up the eyes of policy makers to improve the education system. It is highlighting the need of prioritizing technology in education and for schools and equipment to become modernized. It is an opportunity to rebuild a stronger education, addressing the gaps. We need to use this as an opportunity to bring back every child that has been left behind even before COVID-19. This is a good opportunity for everyone to come back to the system (Key informant, Regional, May 2021).

The world was so caught off-guard with the unprecedented pandemic that other challenges began to pale in comparison. The issue of getting pregnant and parenting girls back into school has always faced opposition, but suddenly the barriers started to diminish during COVID-19, and people started focusing on 'Let's get these girls back to school.' We have been working for the past 6 years to get all girls to return to school, regardless of their parenthood status, but it was during the pandemic that the stakeholders began to feel that this task was more doable than ever (Key informant, Kenya, May 2021).

The silver lining has been around the emphasis on girls' empowerment. The world has many problems: COVID-19, climate change, etc., but the pandemic showed that the work to empower girls and women is still relevant and much needed. It justifies why we work hard and continue to exist. ... COVID-19 unmasked so much that still needs to be done by the organizations that work for children and girls/women. ... Anything that happens, the women get affected twice [as much by it], and COVID-19 demonstrated this (Key informant, Uganda, June 2021). 
"COVID-19 is a blessing in disguise because it has opened up the minds of the government and the civil society organizations that there is a need to invest more in specific challenges and problems which are affecting the girls mostly."

Emmy Zoomlamai Okello

Foundation for Inclusive Community Help (FICH)

Passionately serving Northern Uganda's youth and women

Other opportunities cited by the key informants included the responsiveness and the dedication of teachers in pandemic times, the willingness of some girls to continue learning, and effective parental support.

It is also noteworthy that organizations were clearly prepared to take advantage of the opportunities that presented themselves during COVID-19. Community-based and other kinds of organizations were responsive, agile, and effective when the pandemic hit - able to demonstrate their strength and respond to community needs rapidly. They were flexible and innovative, able to adjust and tailor their programs. Being embedded in communities, they were also well-positioned to resolve emerging problems. This became even clearer when international actors were unable to intervene, especially when country borders closed during the pandemic. Importantly, these organization also had ready solutions to offer to governments and communities at a time when the latter were seeking immediate responses.

"There were opportunities for organizations and leaders who were willing to be agile and were aware of what was happening. These tended to be those who were rooted in their communities because it allows you to realize what's happening and respond with empathy and make impactful change profound for these communities. The organizations that were able to grow and excel in the time of COVID-19 were such organizations."

Deborah Kimathi

Dignitas-Dignity through education

Additionally, while facing the enormous challenge that COVID-19 symbolized, civil society organizations were open about their own individual limitations, and consequently called for an inter-disciplinary approach, in which organizations work collaboratively and complement/supplement each another, making efficient use of available resources. While there is always the possibility that civil society organizations would compete with one another, respondents acknowledged that a sole organization could only go so far in resolving pandemic problems. In the words of one interviewee, 'The problems that we work on need a multi-sectoral, interdisciplinary approach' (Key informant, Uganda, June 2021). 
The opportunities outlined by study participants, and the ways of harnessing them, are connected to the actual solutions that participants offered for addressing current problems in girls' education. Respondents' narratives pointed to a number of ways in which current problems in girls' education in East Africa can be addressed in order to accelerate girls' re-entry into school and ensure a quality learning experience. Both shortand longer-term solutions for addressing these problems were highlighted and are presented in subsequent sub-sections.

\section{Short-term solutions}

\section{Basic needs}

Study participants contended that interventions for ensuring girls' well-being were required before girls could actually learn. Overlooking girls' basic needs while attempting to promote their re-enrollment in school was considered as being counterproductive. As key informants indicated:

Girls have a variety of reasons why they have a hard time coming back to school, so the short-term interventions to re-enroll them back to school need to consider this. The differing needs of girls have to be met (Key informant, Uganda, June 2021).

This is not a long-term solution, and there is no easy answer. They [the solutions] could help build toward what we want to achieve in the long-term (Key informant, Kenya, May 2021).

Indeed, respondents indicated that some of the most successful programs that experienced minimum attrition of girls during the pandemic period were those that combined innovative means of continued learning with the distribution of basic materials. For example, one secondary school organized a relief program on a monthly basis: Girls were directed to come to school in small groups to obtain food, menstrual products, soap, and transportation funds for the trip back home. Smart phones were also purchased for the girls to circumvent exploitation by predators who used girls' need for technological devices as an entry point for exploiting and sexually abusing vulnerable girls.

A program in Tanzania identified the poorest, most vulnerable girls, struggling to return to school, providing for their school-based needs (e.g., uniforms, school fees, hostel accommodation for those living far from schools, and individualized support, such as shoes for girls that had none), while avoiding the provision of actual cash. However, a randomized control study on cash transfers demonstrated that unconditional cash transfers promoted girls school re-enrollment (Population Council, forthcoming). As a key informant further explained:

It does not necessarily need to be in the form of cash transfers to households, but any ways to reduce the cost of students returning to school (for example, school fee waivers) would be helpful. Social protection in the time of the pandemic has been important unconditional cash transfers to households, and just general approaches to reduce the costs of schooling (Key informant, Kenya, May 2021). 
Notably, some of the interventions evaluated as 'bad buys' in terms of cost-effectiveness by the Global Education Evidence Advisory Panel Report (2020) (e.g., cash transfers and the provision of devices and textbooks) are the very ones that key informants emphasized as being necessary for getting girls back into school. Clearly, in the unique, emergency context of COVID-19, the provision of inputs such as additional textbooks, teachers, devices such as smart phones and radios, and cash transfers, could make a vital difference in girls' ability to continue with their education.

\section{Psychosocial support}

The importance of psychosocial support for girls as a short-term measure was emphasized by all organizations working on education and gender. Several observed that the need was especially great for girls that had experienced GBV and pregnancy during the pandemic, but that adults in the education sector (teachers, etc.) also required such support:

There is an aggressive back-to-school campaign going on especially targeting pregnant and parenting girls currently in Kenya, but the psycho-social support for these girls is still lacking. Many girls found themselves pregnant against their will either by abuse or by needing money, and their circumstances are often vulnerable to start with. Pregnancy is the end result. We need to ask, how are these girls doing mentally? Dealing with rejections from the family, the school, the person who caused the pregnancy? ... Considering the East African context, the president that just passed away in Tanzania had said, 'You being pregnant, it means that you should not go back to school because you will corrupt other girls.' Such stigma is more than what a girl can bear. The girl may have been the hope of the family, and by getting pregnant, the girl had disappointed them. This puts a lot of strain of the girls (Key informant, Regional, May 2021).

One organization obtained emergency support funding to expand their work with victims of incest, given the increased need during the pandemic. This intervention involves working with the police to promote victims' access to treatment and the care. Another organization began developing a curriculum on trauma around child abuse and corporal punishment in schools. There is a gap, however, in psychosocial support interventions for adults in the education sector.

\section{Keeping children engaged in learning during school closure}

Civil society organizations that worked to keep children engaged in learning during school closure had several solutions for doing so, including by systematically organizing community-based learning gatherings of a small number of students, in addition to maintaining close contact with students through a range of mechanisms (e.g., via phone, home visits, and periodic school openings).

Organizations also harnessed their existing structures to meet the changing needs of the education sector during COVID-19. For example, Education Development Trust already conducted interventions at both school and household levels, reaching around 500 primary schools, and aiming to work with 70,000 girls in Kenya. Government community health workers (CHWs) are embedded in this household level structure, and were 
therefore used to visit the homesteads with education information and resources during the pandemic, along with other community groups that had been trained to hold tutorials with girls.

Education Development Trust also fostered new entries into the workplace, and the creation of a workforce under pandemic circumstances, drawing on tertiary students who were just about to complete their teachers' training, and who were ready to provide volunteer support; a team of teachers who were willing to do the same; and other highly skilled and motivated people that were eager to visit students' homes. The academic assessment of students within this program indicated that there was no learning loss among participants during the school closure.

Other organizations harnessed the presence of youth in their communities, combining community youth engagement with children's education. Harnessing young people's time and energy, Grassroots Innovations for Change involved them in children's education by giving them study group facilitator roles. This proved to be positive for both this NGO and the youth concerned.

Some organizations began to explore experiential and real-life learning outside of classroom as a result of school closures. Realizing just how much there was to learn from the home environment, organizations worked with parents to bring learning to life by involving children in baking, gardening, and animal care.

In Kenya, the Ministry of Education (MoE), in collaboration with the Population Council, took advantage of the school closure period to prepare parenting and pregnant girls to return to primary school once schools reopened. In partnership with head teachers, chiefs, and village elders, MoE Curriculum Support Officers identified girls who had dropped out of school due to pregnancy pre-COVID, tracked them down to their homes, and shared information about Kenya's school re-entry policy and the benefits of education with their families, encouraging girls to return to school when the time came (Gachoya et al., 2021).

\section{Longer-term solutions}

\section{Parental engagement}

The need to engage parents in their children's learning received renewed attention as a result of COVID-19, but was also regarded as an approach that should transcend pandemic conditions, given its role in strengthening the learning experiences of children within and outside the context of emergencies. Respondents involved in such interventions opined that when parental engagement occurred in a positive way, a significant impact was made on the children's learning and well-being.

The challenges of engaging with non-literate parents (particularly, those in rural settings) emerged as a common theme among respondents. One organization approached this issue by introducing adult education classes into their programming, noting that this led 
to a change in parents, who developed a positive attitude towards their children's education. One respondent had the following to say:

The parents need to understand and encourage girls to study, continue their education, and to fight for their dreams. The education can lead the girls to have a good life and help out their parents in the future, but more importantly help themselves - even if there is no job available, the girls can find ways to start business on their own (Key informant, Tanzania, May 2021).

Respondents suggested that parental engagement was a relatively untapped domain in the education sector, and that much more needed to be done to harness the potential of parents to support children's education. Respondents provided suggestions for making progress in this domain, including engaging parents through the provision of basic information, as well as existing mechanisms for doing so with ease:

There are no tips and guidance as to what parents are supposed to do and now that schools have re-opened they do not communicate properly with parents in terms of time schedule [or] reassurance about further disruption from COVID-19. The information has not been proper in reducing people's anxieties resulting from all the uncertainty. For example, in Kenya, there is a very good system of local administration (village elders, chiefs). These are the people that could communicate to parents all the necessary information about education and abuse. But the existing structure has not been used to the benefits of keeping students engaged and ensuring their re-enrolment (Key informant, Kenya, June 2021).

\section{School leadership}

When reflecting on potential solutions, school leadership (including both school heads and teachers) was a recurrent theme among many respondents. Respondents persuasively argued that any long-term solutions to girls' education must involve the meaningful engagement and integration of school leadership, given their pivotal role in shaping how schools work and what is allowed in schools. Key informants also pointed out that even when schools suffer from high turnover of teachers, the school leadership tends to be more stable.

School leaders set school culture: Teachers and others at the school follow their leader, and this is how organizational culture works. If we can shift the school leaders' mindsets, help them hear the girls' voices and see how the barriers play out in the school environment, it allows them to shift the whole school culture (Key informant, Kenya, May 2021).

School leaders have a voice of authority in the community position of influence. They have a voice in administrative circles, [among] village chief, churches, parents' circles, and thus have the influence over them (Key informant, Kenya, May 2021).

Long-term efforts therefore need to focus on clarifying the values of school leadership, which in turn informs the kind of schools that are established, and the extent to which policies and progressive programs are implemented in the region. A baseline survey 
conducted by Dignitas in Kenya found that traditional, patriarchal mindsets persist among school leaders, and are often detrimental to the learning and thriving of girls (Dignitas, 2021). A key informant from Dignitas delved further into these findings:

Our baseline study demonstrated that $31 \%$ of the School Leaders interviewed agreed that 'a man should have the final word about decisions in his home'. Similarly, $23 \%$ of the School Leaders agreed that 'a woman's most important role is being a good homemaker'. Further, $8 \%$ of the School Leaders agreed that 'a woman should tolerate violence to keep her family together'. The education of boys is still prioritized over that of girls. Our baseline study showed that $8 \%$ of school leaders believed 'wives should be less educated than their husbands', and 'boys should get more opportunities/resources for education.' Our baseline study also revealed that $48 \%$ of girls were doing 3 or more hours of housework daily during school closures, while only (33\%) of girls were spending 1-2 hours doing schoolwork. $18 \%$ of girls interviewed did not have a routine that allowed for daily studies (Key informant, Kenya, May 2021).

School leaders were also noted as playing a critical role in the school re-entry of marginalized girls in the region, with studies showing that gaining their support helps to ensure such re-entry occurs (Undie \& Birungi, 2016; Undie et al., 2020). Teachers were observed as being equally critical. As one key informant opined: 'If you motivate the teachers, they motivate the children. The way you treat the teachers is the way they treat the children' (Key informant, Tanzania, May 2021).

One key informant drew attention to the next level of leadership above school leaders, such as Curriculum Support Officers or Quality Assurance Officers within the Ministry of Education:

Just as a school leader influences school culture, they are in a position to influence the school 'system' culture. There is a space to work alongside that level to drive change. This is often the missing piece. This is sometimes where the government engagement and program implementation could overlap (Key informant, Kenya, May 2021).

\section{Digital literacy and access}

Several informants highlighted the critical need to accelerate the digitalization of education and to narrow the digital divide that is currently widespread:

We have been trying to integrate ICT in education for a long time. There was resistance from a number of stakeholders on this. But COVID-19 has demonstrated the urgent need for ICT integration in education. It has made sure that, going forward, ICT will help make our education system more robust. The pandemic has thrown all of us in this situation, but how we will respond will be another matter (Key informant, Kenya, May 2021).

Digital innovation towards improving learning needs to be accompanied by exploring cost- effective approaches to enhance digital literacy to the community, schools, and women. The commitment of government to invest in education technology used to be lower, and the pandemic changed this. Now there is an 
increased commitment, the educational sector is under review and the focus is on how digital learning is implemented and prioritized (Key informant, Tanzania, June 2021).

Specific solutions around narrowing the digital divide did not emerge from the interviews; however, it was clear that the present time is an opportune one for developing such solutions.

Digitalization is changing the content, means, and reach of education (once target audiences have access). Some organizations increased their outreach during the pandemic by reverting to virtual mechanisms, and more students were able to benefit from their programs:

Because we were not in the field, we managed to reach out to more people virtually, engage with media, other organizations, and the government. It became very easy to reach out and we soon realized that if we invest in online interactions, we can pass our messages to other stakeholders, even outside Tanzania. We enhanced our capacity to work online, and it was an opportunity for us to grow, receive more visibility (Key informant, Tanzania, June 2021).

Nevertheless, the question remains about how to moderate the widening digital divide, ensuring that no child is left behind in an increasingly digital world.

\section{Collaboration with the government}

Many respondents collaborated with the government during the pandemic times, and saw this as a mutually beneficial, and sustainable approach to addressing current problems in girls' education: The government valued the expertise and experience of the civil society organizations, and the collaborative work benefited a greater number of people than would have been the case without government collaboration. Furthermore, at the onset of COVID-19, governments were seeking rapid, innovative solutions and responses in the education sector. Organizations that were able to capitalize on this situation spoke of the unprecedented gains:

The Emanyata Secondary School is a community school that Pastoral Women's Council (PWC) has managed since 2006. The school follows the national curriculum and students take the National Secondary Examinations during the fourth year as with all other schools in Tanzania. The home learning packages distributed to students during COVID-19 were prepared by teachers from the school under the supervision of the District Education Officer (DEO), and thereafter they worked together to distribute the package to homesteads within Ngorongoro district (a pastoralist district). The DEO was very happy with it and was motivated to encourage all other government schools in the district to distribute the home package to the students who were at home. When distributing, we were also going there with the government officials. When we were having radio sessions/programs, PWC had the education officer and the social welfare officer joining 
in, who insisted on protecting girls from violence. The government was very supportive during these unprecedented times (Key informant, Tanzania).

COVID-19 brought Raising Voices much closer to the government and the Ministry in terms of their advocacy. This was not the case before, but the government realized that they could not solve these issues alone and sought help from the CSOs [Civil Society Organizations], including Raising Voices. The government held many online meetings. Raising Voices worked collaboratively and even trained the government officials amidst the pandemic, regarding what violence is, what are alternatives, and what we should do. This is how the " 5,000 school" project came into being, in thinking how to provide the minimum to a greater number of schools. They also visited the sites with the officials and provided data to them. They appreciate the government for taking these leaps. Raising Voices did some of the largest media campaigns ever at this time of COVID-19 (Key informant, Uganda).

Even respondents who were less successful at engaging with the government in these ways acknowledged the benefits of doing so: "[It is] not always easy to collaborate, but the government is the gatekeeper. If you can find one or two people interested in what you do, they can take it very far through their internal circles and result in fruitful collaboration (Key informant, Uganda, June 2021).

\section{Transformative education for girls}

Several of the organizations interviewed indicated that their work had been in emergency, 'fire-fighting' mode since the pandemic, with a need to rapidly change their operation modalities to ensure their programs continued to serve girls and communities. However, the pandemic also obligated them to begin to pose deeper questions about the current education system, the quality of education, what education should look like, and transformative education for girls.

The education and gender experts interviewed in the region opined that the weaknesses in the current education system were unmasked by COVID-19, leading to a realization that, without improvement in quality and nature of education, more students will be left behind. Respondents posed questions such as: Is there any point in girls returning to school if they feel unwelcome and if schools do not offer what they are supposed to? Should girls be blamed for opting to continue with their income generating activities when education does not improve their employability and equip them with the skills to navigate their lives?

\section{In their words:}

We need to review the education systems and skills provided to the young people as they might not be adequate. We may be missing something in the current system for the girls and youth. We need to re-strategize ... If we look at education from a holistic point of view, what does it mean and what does it entail? (Key informant, Uganda, June 2021)

Girls have not been taught how to strive. The 'how' is very important in girls' education. The girls first need the right skills, and second, the right support (Key informant, Tanzania, May 2021). 
Teachers, school leaders, parents and communities need to be part of the solution. If children are not in school, they are somewhere. We need to develop their confidence that if we let children [abandon their livelihoods in order to] go to school, this will add value. A holistic approach is needed that considers all pieces that focus on quality. If we are dragging children back to school where they do not learn and [we]provide no opportunity, then what's the point?" (Key informant, Kenya, May 2021)

Culture and norms are not positive for the girl child to go to school. They also have formal education, but no alternative pathway for sustaining livelihoods. They are not taught skills on how to go on in life. Even if you have education, you might not get a job easily. The parents will say, 'We sent her to school, and she completed it, but she could not find a job.' Then, why should the girls go to school? (Key informant, Tanzania, May 2021)

The exact process and content that would lead to transformative education for girls was not spelt out by respondents; however, there was a sense that change was needed. Furthermore, the programs implemented by some organizations provided possible leads. For instance, several organizations focused on providing life skills course to girls, covering topics such as study skills, personal leadership, sexual and reproductive health and rights, and self-confidence. Others developed mentorship and leadership programs for girls that formed a support system, or established gender-responsive schools.

"Schools need to be engineered to be a place where girls are being empowered. It is not currently girl friendly. They go to school, they may graduate, but they are not being really liberated by the schools. They are not feeling equal to their male counterparts, even when they are doing better than their male counterparts in terms of academic performance. Girls come out of school feeling subordinate to the male counterparts. This points out to the problem in the school system and the set-up.

We need to look back and ask, "What do we want as a product of the school system?" Is it someone who passed the exam and is obedient and get a job and live by the existing norms? Or is it someone who has been educated in a way that can stand up to the norms that are not necessarily progressive?

The current school system is not helpful to girl's agenda. It maintains the status quo. You get the education so that you live by the same old norms." 


\section{Way Forward}

During a two-day virtual meeting entitled, Girl's Education and COVID-19: An Interactive, Participatory Forum for East Africans to Tackle Emerging Challenges and Define Solutions, education stakeholders from Kenya, Tanzania, and Uganda collectively considered the evidence presented in this report and concurred on the need for a plan for the region to proactively tackle the current and future crises in the education sector. Emphasis was laid on the need to ensure a multi-sectoral response (including education and other sectors) to COVID-19 and other crises. In some contexts, COVID-19 was initially viewed and addressed as purely a health issue, leading to the exclusion of the education sector's in COVID-19 response preparations. It is now evident, however, that a comprehensive response is required if the pandemic is to be adequately addressed in the region.

\begin{tabular}{|c|c|}
\hline \multicolumn{2}{|r|}{ Summary of Recommended Actions } \\
\hline o & $\begin{array}{l}\text { Center girls in crises response and } \\
\text { prevention initiatives }\end{array}$ \\
\hline O & Address reproductive health concerns \\
\hline ○ & $\begin{array}{l}\text { Address mental health/psychosocial } \\
\text { support needs }\end{array}$ \\
\hline ○ & $\begin{array}{l}\text { Implement education financing } \\
\text { interventions }\end{array}$ \\
\hline O & Engage parents \\
\hline O & Harness existing community resources \\
\hline O & Foster preparedness for digital learning \\
\hline O & Re-think education \\
\hline O & Generate, disseminate, and use evidence \\
\hline & $\begin{array}{l}\text { Employ a collaborative approach to } \\
\text { working with government }\end{array}$ \\
\hline
\end{tabular}

With regard to the way forward (i.e.: Where should the education sector go from here, and what should it focus on henceforth, given the ongoing crisis, and the likelihood of future ones?), the narratives of education stakeholders during the two-day convening revolved around 10 main issues. These issues and the recommended actions around them are summarized below.

\section{Center Girls in Crises Response and Prevention Initiatives}

- Ensure that girls are at the center of responses as active agents in agenda- and priority-setting within the education sector. Build their capacity to do so.

- Empower boys in a similar fashion, with a view to their being able to work alongside girls in addressing gender inequalities.

- Highlight/document the ways in which girls are already playing active roles in responding to crises, as well as existing mechanisms for obtaining regular input from girls into program and policy development.

\section{Address Reproductive Health Concerns}

- Employ context-appropriate comprehensive sexuality education as a tool for addressing the range of emerging reproductive health concerns faced by girls during COVID-19. 
- Develop interventions to attend to the childcare needs of parenting girls returning to school.

- Conduct social norms change interventions to help foster school re-entry and retention for pregnant and parenting girls, including those who are widowed and/or household heads. Glean lessons from existing interventions in this area.

\section{Address Mental Health/Psychosocial Support Needs}

- Curtail school closures in recognition of the fact that, in addition to preventing learning loss, physical school attendance can offer social protection to girls when homes do not, while also protecting girls' mental health.

- Strengthen school-based guidance and counseling to help attend to emerging mental health and psychosocial issues. This includes bolstering linkages between child protection and mental health services, and schools.

- Develop self-care programs for teachers to ensure their mental health and psychosocial support needs are also met.

- Expand menstrual hygiene product access points beyond schools alone (e.g., community safe spaces), to ensure continuous access for girls. Also consider incorporating the production of menstrual hygiene products into life skills-building programs for girls.

- Integrate feeding programs/nutritional support into schools to temper the dire economic effects of the pandemic.

\section{Implement Education Financing Interventions}

- Implement education financing interventions to address private school closures in the context of economic constraints, helping to ensure that more girls have schools to return to.

- Introduce and customize inclusive scholarships and bursaries to support children and families in need, without discriminating against marginalized girls (e.g., pregnant/parenting, widowed, or household head girls).

\section{Engage Parents}

- Strengthen the skills of parents to support and be involved in their children's learning on a regular basis, tailoring interventions to attend to both literate and non-literate parents. This would entail both (home- and school-based) academic and behavioral support; the communication skills necessary to accomplish this; confidence-building of parents; and digital and literacy skills-strengthening.

- Collate evidence-based and practice-based parental engagement interventions already being implemented to enhance understanding of how to empower parents to support learning. 
- Institutionalize parental engagement within the education system, in order for parents (both mothers and fathers) to serve as empowered partners, and to create linkages between parents, students and community leaders.

- Enhance ability of economically-constrained parents to send their children back to school by introducing economic-strengthening interventions (e.g., training in business start-up, agri-business, subsistence farming, etc.)

\section{Harness Existing Community Resources}

- In future crises, use public school teachers (who were homebound, paid, and largely unutilized when COVID-19 first hit the region) and school leaders as resources to support children's learning. This will require the preparation and support of school teachers and leaders to play this role - and the conceptualization of how such support should be designed in crises.

- Use the range of other community resources to support children's learning in creative ways (e.g., university students and other young people, retirees, program alumni, undergraduates and new/unemployed graduates, etc.).

- Form community-based education committees to help foster/support learning.

- Use community-based champions/advocates to convey messages about the need to ensure (and the benefits of ensuring) girls return to school.

\section{Foster Preparedness for Digital Learning}

- Invest in child protection and safeguarding in the context of digital learning to mitigate the risks that educational technology can pose for children.

- Invest in affordable, accessible digital learning mechanisms.

- Extend digitalization beyond schools alone to include other community spaces.

- Prepare for the realities of 'no-tech': In areas without internet connectivity, notech, low-cost solutions should be implemented to sustain learning.

- Given the digital divide, also invest in low-cost learning solutions to prepare for future crises - e.g., learning material distribution, radios and radio masts for communities, etc.

\section{Re-Think Education}

- The rationale for education

- At the policy level, interrogate universal primary education to determine what it should/can be in the current era, and what for.

- Deliberate on the gender transformative nature of education, and how this can be applied for the benefit of girls.

- The content of education

- Determine the actual requirements for career pathways, and design education programs accordingly:

- Complement traditional schooling with skills-building (including for income-generation and well-being). 
- Establish/strengthen apprenticeship programs and technical institutions as an alternative to conventional schools.

- Establish/strengthen 'second-chance' education programs.

- The flexibility of education

- Consider whether entry requirements for technical institutions can be modified to remove barriers to entry and increase access.

- Employ flexible learning approaches for students, including self-directed and self-based learning.

\section{Generate, Disseminate, and Use Evidence}

- Generate and document quantitative, quantitative, and program/practice-based evidence on:

○ 'Missing' girls: The baseline information, and the magnitude of the problem; the migration specifics.

- Rural, nomadic, special needs (and other marginalized) populations

- Long-term (rather than just immediate) effects of COVID-19 on learning outcomes and associated solutions: Learning loss at the level of the individual child - how to assess and resolve this.

- Wherever possible, ensure that data are disaggregated by gender.

- Ensure that findings emerging from collected evidence are shared with study participants.

- Use evidence to inform programming, or implement evidence-based approaches.

\section{Employ a collective approach to working with government}

- As NGOs and other partner types, engage with government collectively to deliver education innovatively during and post-COVID, and to share evidence coherently 'with one voice.'

- Map solutions to determine who is doing what, where, and to help leverage such solutions toward a shared and holistic goal.

- Establish 'girls in crisis' working groups that would bring together government and non-government partners.

Existing education sector COVID-19 response plans in the East African region have necessarily been illustrative or tentative in the context of this unprecedented pandemic. However, a year and a half in, evidence on the state of girls' education has accumulated, providing an opportunity to weigh existing responses to, and plans for, girls' education in the region against such evidence. Findings and recommendations from the present study can be used as a starting point for this exercise, informing the adaptation and implementation of education sector COVID-19 responses in East Africa. 


\section{Bibliography}

CAMFED Tanzania. 2021. Unpublished program data.

Dignitas. 2021. Creating gender-inclusive schools during COVID-19.

https://dignitasproject.org/project-kanya-equipping-school-leaders-bring-girls-backschool/.

Echidna Giving. 2021. Advancing girls' education in light of COVID-19 in East Africa. Concept Note.

FAWE (Forum for African Women Educationalists) Uganda. 2021. The situation of, and impact of COVID-19 on school-going girls and young women in Uganda.

https://faweuganda.org/wp-content/uploads/2021/06/COVID-19-Impact-Study-on-Girlsin-Uganda-2020.pdf.

Flowe, H.D., Rockowitz, S., Rockey, J., Kanja, W., Kamau, C., Collof, M., Kauldar, J., Woodhams, J., Colloff, M., Davies, K. 2020. Sexual and other forms of violence during the COVID-19 pandemic emergency in Kenya: Patterns of violence and impacts on women and girls. https://doi.org/10.31234/osf.io/eafwu.

Gachoya, A., Kirongo, T., Kiiru, F., Odwe, G., Undie, C. 2021. Reopening in the time of COVID-19 in Kenya. Regional Education Learning Initiative Newsletter https://reliafrica.org/re-opening-in-the-time-of-covid-19-in-kenya/.

Global Education Evidence Advisory Panel. 2020. Cost-effective approaches to improve global learning: What does recent evidence tell us are "smart buys" for improving learning in low- and middle-income countries?

https://documents1.worldbank.org/curated/en/719211603835247448/pdf/CostEffective-Approaches-to-Improve-Global-Learning-What-Does-Recent-Evidence-Tell-Us-AreSmart-Buys-for-Improving-Learning-in-Low-and-Middle-Income-Countries.pdf.

Grass Roots Innovations for Change (GRIC). 2020. Rapid assessment report on the impact of COVID-19 on learning for vulnerable students in Kajiado, Laikipia North, and the Informal Settlements in Nairobi.

Human Rights Watch. 2020. Tanzania: World Bank okays discriminatory education loan Should require end to ban on pregnant girls' schooling. https://www.hrw.org/news/2020/04/02/tanzania-world-bank-okays-discriminatoryeducation-loan.

Initiative for Social and Economic Rights (ISER). 2020. Leaving no one behind: Barriers to continuity of education for vulnerable children impacted by COVID-19 in Uganda.

https://www.iser-

uganda.org/images/downloads/Barriers to Continuity_of_Education_for_Vulnerable_Ch ildren Impacted by Covid-19 in Uganda.pdf.

ISER. 2021. "I must work to eat": COVID-19, poverty, and child labor in Ghana, Nepal, and Uganda. https://www.iser-uganda.org/images/downloads/I_Must_Work to Eat.pdf. 
Insights for Education. 2021. One year of school disruption. https://education.org/factsand-insights.

International Center for Research on Women (ICRW). 2020. REBUILD: COVID-19 and women in the information economy in Kenya, Uganda, and India.

https://www.icrw.org/research-programs/assessing-covid-policy-impact-on-informalworkers-in-kenya-uganda/.

International Telecommunications Union. ICT Facts and Figures. 2017.

https://www.itu.int/en/ITUD/Statistics/Documents/facts/ICTFactsFigures2017.pdf.

Kansiime, M. K., Tambo, J. A., Mugambi, I., Bundi, M., Kara, A., Owuor, C. 2021. COVID19 implications on household income and food security in Kenya and Uganda: Findings from a rapid assessment. World Dev. 137:105199.

https://www.sciencedirect.com/science/article/pii/S0305750X20303260?via\%3Dihub.

Kenya Executive Office of the President and Population Council. 2021. The social, health, education and economic effects of COVID-19 on adolescent girls in Kenya: Responses from data collection in five Nairobi information settlements (Kibera, Huruma, Kariobangi, Dandora, and Mathare) June, 2020.

https://www.popcouncil.org/uploads/pdfs/2020PGY_Covid_KenyaAdol_Nairobi.pdf.

Kenya Executive Office of the President and Population Council. 2021. Promises to keep: Impact of COVID-19 on adolescents in Kenya.

https://www.popcouncil.org/uploads/pdfs/2021PGY ImpactCovidAdolKenya.pdf.

Malala Fund. 2020. Girls' education and COVID-19: What past shocks can teach us about mitigating the impact of pandemics.

https://downloads.ctfassets.net/0oan5gk9rgbh/6TMYLYAcUpjhQpXLDgmdla/3e1c12d8 d827985ef2b4e815a3a6da1f/COVID19 GirlsEducation_corrected_071420.pdf.

Masago, M. O., Sambu, A., Kweingoti, G. R., Jebet, S. Bakari, C., Kelele, J. (2020), Effects of COVID-19 pandemic on the welfare of the Maasai girl child in Narok County, Kenya. European Journal of Social Sciences 3(3): 123-141.

https://journals.euser.org/files/articles/ejss_v3 i3 20/Masago.pdf.

Ministry of Education, Republic of Kenya. 2020. National guidelines for school re-entry in early learning and basic education.

https://www.popcouncil.org/uploads/pdfs/2020RH_NationalSchoolReEntryGuidelines.p df

Ministry of Education and Sports, Uganda, 2020. Revised guidelines for the prevention and management of teenage pregnancy in school settings in Uganda.

https://www.ungei.org/sites/default/files/2021-02/Revised-Guidelines-PreventionManagement\%20-Teenage-Pregnancy-School-Settings-Uganda-2020-eng.pdf.

Ministry of Education, Science, Technology and Sports, Uganda. 2016. A study on linkage between pregnancy and school dropout in Uganda. Study Report. 
Ministry of Public Health and Sanitation \& Ministry of Education, Government of Kenya. 2009. National School Health Policy. Republic of Kenya.

Ministry of Education \& Ministry of Health, Government of Kenya. 2018. Kenya School Health Policy. Republic of Kenya.

https://www.ncikenya.or.ke/documents/KENYA\%20SCHOOL\%20HEALTH\%2OPOLICY\%2 OBOOK\%20 20 11_2018.pdf.

Population Council. (forthcoming). Cash transfers to stimulate school re-enrollment among vulnerable adolescent girls in urban informal settlements as Kenya responds to COVID-19.

PMA Agile/Gender \& ICRHK. 2020. Gender and COVID-19: Transactional partnerships and sex trade. Baltimore, MD, USA: Bill \& Melinda Gates Institute for Population and Reproductive Health, Johns Hopkins University Bloomberg School of Public Health. https://www.pmadata.org/sites/default/files/data_product results/PMA\%20Gender\%2 OCOVID\%20Transactional\%20Sex\%202020.pdf.

Rafaeli, T. and Hutchinson, G. (2020). The secondary impacts of COVID-19 on women and girls in sub-Saharan Africa. K4D Helpdesk Report 830. Brighton, UK: Institute of Development Studies.

Save the Children. 2020. Save the Children Protection Assessment on the Impact of COVID-19 in Uganda https://resourcecentre.savethechildren.net/library/save-childrenprotection-assessment-impact-COVID-19-uganda.

Sserwanja, Q., Kawuki, J., Kim, J.H. 2021. Increased child abuse in Uganda amidst COVID-19 pandemic. J Paediatr Child Health. 57(2):188-191.

Stevens, L.M., Rockey, J.C., Rockowitz, S.R., Kanja, W., Colloff, M.F., Flowe, H.D., 2021. Children's vulnerability to sexual violence during COVID-19 in Kenya: Recommendations for the future. Front. Glob. Womens Health. https://www.frontiersin.org/articles/10.3389/fgwh.2021.630901/full.

Undie, C. \& Birungi, H. 2016. Are school principals 'the bad guys'? : Nuancing the narrative of school re-entry policy implementation in Kenya. In A. Okwany \& R. Wazir (eds.). Changing Social Norms to Universalize Girls' Education in East Africa: Lessons from a Pilot Project (pp. 166-183). Garant Publishers.

https://www.popcouncil.org/uploads/pdfs/2016RH_SchoolPrincipals chapter.pdf.

Undie, C., Birungi, H., Odwe, G., Onyango, F. 2020. Final evaluation results: Expanding access to secondary school education for teenage mothers in Homa Bay County. https://www.popcouncil.org/uploads/pdfs/2020RH_Phase_I_Evaluation_Results_Kenya .pdf.

UNESCO. 2021. COVID-19 impact on education. https://en.unesco.org/themes/education-emergencies/coronavirus-school-closures 
Uwezo. 2020. Are our children learning? The status of remote-learning among schoolgoing children in Kenya during the COVID-19 crisis. Nairobi: Usawa Agenda.

https://usawaagenda.org/project/are-our-children-learning/. 


\section{Annexes}

\section{A1. LIST OF ORGANIZATIONS INTERVIEWED}

\begin{tabular}{|l|}
\hline Kenya \\
\hline African Population and Health Research Center \\
\hline Big Picture Learning \\
\hline Dignitas \\
\hline Education Development Trust \\
\hline Kakenya's Dream \\
\hline Plan International \\
\hline Population Council \\
\hline Usawa Agenda \\
\hline WISER International \\
\hline Tanzania \\
\hline AfricAid \\
\hline HakiElimu \\
\hline Milele Zanzibar Foundation \\
\hline Pastoral Women's Council \\
\hline Room to Read, Tanzania \\
\hline Uganda \\
\hline Educate! \\
\hline FAWE Uganda \\
\hline Foundation for Inclusive Community Help \\
\hline Girl Up Initiative Uganda \\
\hline Initiative for Social and Economic Rights \\
\hline Raising Voices \\
\hline Regional \\
\hline Amplify, Kenya \\
\hline Camfed, Tanzania \\
\hline FEMNET, Kenya \\
\hline Girl Up, Kenya \\
\hline GRIC, Kenya \\
\hline Human Rights Watch, Kenya \\
\hline ICRW Kenya/Uganda \\
\hline
\end{tabular}




\title{
A2. INTERVIEW GUIDE
}

\author{
Key Informant Interview Guide \\ Getting Girls Back into School in East Africa \\ Population Council
}

Thank you so much for your willingness to take part in this interview. My name is [Name]. In collaboration with stakeholders within the girls' education sector in East Africa (including the Equity and Inclusion Thematic Group of the Regional Education Learning Initiative [RELI]), the Population Council is conducting a number of interviews to learn from on-the-ground experiences of, and research by, East African organizations to understand how COVID-19 has affected girls' education, and what near-term efforts are needed to ensure girls get back to school and learn.

These interviews are the first step in an effort to learn from the East African girls' education sector about problems caused by COVID-19. This step will be followed by sharing a synthesis of what we learn through these interviews and a desk review, both of which will inform a stakeholders meeting to co-create solutions.

We are talking to representatives of NGOs who have been working on girls' education during COVID-19, or who work on gender issues in general and may therefore have helpful insights. We would like to gain an understanding of what has been happening with girls' education in your country, or the East African region more broadly since COVID19 hit, particularly with the various school closures and re-openings and that your country or the region might have experienced. I would therefore like to hear about your own impressions, observations, experiences in this regard, along with any data that your organization might have collected internally, or from the communities you work in.

The interview will take about an hour of your time. As indicated in the consent form, I will be recording the interview. Although I have specific questions, you can talk about anything you think is important for us to know. I also want to remind you that everything we talk about today is confidential. Whenever we write a report, we will not use any names in the report so no one can identify you. If there are any questions you would rather not answer, just let me know.

Remember, there are no "right" or "wrong" answers to any of the questions we will be asking. We would just like to hear about your own impressions, experiences, observations, or feelings in regard to whatever we ask. Your honest responses (whether 'negative' or 'positive) will help us learn lessons, identify gaps, and generate solutions. If any questions make you uncomfortable, you do not have to answer them. Just let me know and we'll move on to the next question. 


\section{Introduction}

1. [For organizations working specifically on girls' education]: To get us started off, would you mind telling me about the girls' education work your organization is carrying out in the context of COVID$19 ?$

[For organizations not working specifically on girls' education]: To get us started off, would you mind telling me about any education work your organization might be doing with children or youth during COVID-19?

- How is your organizations' approach to education work different for girls versus boys, if at all, during COVID-19 - and why?

2. The pandemic has created a very challenging environment for most programs in East Africa. When you think about your [girls' education/gender] work, what are some of the most challenging issues that have emerged in the context of COVID-19?

- How have you managed to deal with these issues, if at all?

3. When you think about your [girls' education/gender] work, what are some of the most surprising or unexpected issues that have arisen in the context of COVID-19?

- Please say more about that.

4. And, when you think about your [girls' education/gender] work, what are some of the greatest opportunities that have emerged in the context of COVID-19?

- Please tell me more about that.

\section{Understanding the Current Problems}

This has been very interesting so far - so, thank you! Now, let's move on to understanding some specific, current problems in girls' education, from your perspective, during COVID-19.

1. Based on your organization's experiences, what would you say are the main problems facing girls' education today, in these COVID times?

2. When you think about the current problems that your organization has observed in regard to girls' education during COVID, to what extent would you say these problems are brand new, as opposed to being pre-existing (i.e., pre-COVID) problems? Please elaborate.

- [Referring to any new problems]: In what ways has COVID-19 created, or contributed to creating, these new problems?

$\circ \quad$ [Referring to any pre-existing problems]: In what ways has COVID-19 changed or affected these pre-existing/old problems - whether negatively or positively?

3. Are primary and secondary schools currently open in the settings in which you work in East Africa?

- If yes, what (if anything) are you seeing when it comes to girls re-enrolling in school since COVID-19?

i. To what extent would you say girls' re-enrollment is happening?

ii. If you were asked to give an estimate, what percentage of girls would you say are not re-enrolling?

- What are the barriers you're seeing to girls re-enrolling?

- Which girls seem to be facing these barriers much more than others, and why?

- What are the facilitators you're seeing to girls re-enrolling?

4. The issue of learning loss is also a concern globally, during the pandemic. To what extent would you say girls and boys lost learning while they were at home, based on any evidence from your programs/research?

- Which group would you say lost more learning than the other, if at all? Please explain further. 
i. If yes, to what extent would you say there are differences or similarities in girls' access to digital resources, versus boys'?

- What are the best approaches you have seen in this region for keeping children engaged in learning while schools are closed?

\section{Identifying Gaps in Our Understanding}

1. As you can see, I've been asking a series of questions to better understand what the current issues are in girls' education as a consequence of COVID-19. However, it is likely that there are other important issues I haven't even considered. In order to put together an effective response for girls' education in this region in the time of COVID, what do we need to be considering that we haven't yet touched on in this interview?

- What issues, if any, are your programs/research pointing to that we haven't considered yet?

- What data would you say are needed that we don't have yet?

- What interventions would you say are needed that we haven't begun implementing?

- Is there any literature or research that you're aware of (whether from within your organization or elsewhere) that we should read up on in order to learn more about anything we've asked so far? If so, what would you recommend that we read?

2. We've been focusing on girls' education in COVID-19, but we also realize that girls don't live in isolation. They have families, schools, churches, and other support systems whose experiences under COVID might affect girls' ability to return to school. To what extent are your programs/is your research indicating anything about girls' support persons/systems that we need to be thinking about, too?

\section{Illuminating Solutions}

1. We're nearing the end of the interview, and, once again, your time is appreciated. With all the challenges brought about by COVID-19, we would still like to be able to accelerate girls' re-entry into school and ensure they have a quality learning experience when they do re-enter. How can we address the challenges we've been talking about to achieve school re-entry for girls in the time of COVID, and to ensure a quality learning experience?

- What would 'addressing the challenges' look like? What needs to happen?

- [For those whose organizations that are already working to promote school re-entry for girls during COVID-19]: What messages seem to be resonating with parents or community members to compel them to let girls get back into school in these pandemic times?

i. What messages don't seem to be resonating as much?

\section{Interview Closing:}

- Lastly, given my interest in understanding how COVID-19 has affected girls' education and what near-term efforts are needed to ensure girls get back to school and learn, what should I have asked you that I didn't think to ask? [Have them respond to any question they raise].

That covers everything I wanted to ask. Thanks very much to you for your time today. I have learned so much from you about the realities of girls' education in East Africa during the COVID-19 pandemic. We plan to share the report of the findings from this study with you once it is finalized.

In the meantime, do you have any questions for me? 


\section{A3. PARTICIPANTS LIST}

\section{Girl's Education and COVID-19: An Interactive, Participatory Forum for East Africans to Tackle Emerging Challenges and Define Solutions}

1. Adan Isaac, Population Council

2. Agnes Odhiambo, Human Rights Watch

3. Alethea Osborne, MannionDaniels

4. Alexandra Hall, MannionDaniels

5. Ali Bakar, Milele Zanzibar Foundation

6. Benta Abuya, African Population and Health Research Center

7. Brenda Oulo, Amplify

8. Carolyne Ajema, International Center for Research on Women

9. Chi-Chi Undie, Population Council

10. Dana Schmidt, Echidna Giving

11. Daniel Korinko, Kakenya's Dream

12. Deborah Kimathi, Dignitas

13. Devotha Festo, Africaid

14. Emily Kaiser-Termes, Echidna Giving

15. Emmanuel Manyasa, Usawa Agenda

16. Emmy Zoomlamai, Foundation for Inclusive Community Help

17. Esther Nyawira, FEMNET

18. Erin Ganju, Echidna Giving

19. Eva Nderu, Insights for Education

20. Faith Mbushi, Population Council

21. Gaudence Kapinga, HakiElimu

22. George Odwe, Population Council

23. Halima Zaid, FEMNET

24. Hawa Nabbuye, Educate!

25. Honest Kansiime, Girls to Lead Africa

26. Janet Munyasya, Population Council

27. Jaclyn Makaaru Arinaitwe, Echidna Giving

28. Jill Anami, FEMNET

29. Joyce Malombe, Wellspring Philanthropic Fund

30. Karen Austrian, Population Council

31. Khadija Shariff, Milele Zanzibar Foundation

32. Kim Wright-Violich

33. Lucy Maina, Grassroots Innovations for Change

34. Mara Lipsou, MannionDaniels

35. Margaret Kamau, Education Development Trust

36. Monica Nyiraguhabwa, Girl Up Initiative Uganda

37. Muthoni Mwangi, Girl Up-United Nations Foundation

38. Naomi Kamitha, Forum for African Women Educationalists (FAWE)

39. Robert Clifford

40. Rolla Khadduri, MannionDaniels

41. Rosemary Migiro, Plan

42. Salome Aloo, Impact(Ed)

43. Stella Chege, FAWE

44. Stephanie Gasior, Wellspring Philanthropic Fund

45. Susan Opok, FAWE

46. Suzanne Grant Lewis, Insights for Education

47. Wangui Nyaga, Grassroots Innovations for Change

48. Yoko Akachi, MannionDaniels 


\title{
A4. REGIONAL CONVENING AGENDA
}

\section{Girls' Education and COVID-19: An Interactive, Participatory Forum for East Africans to Tackle Emerging Challenges and Define Solutions}

\author{
July 12-13, 2021; 16:00-18:30 East African Time \\ (Virtual meeting)
}

In March 2020, more than 90\% of countries worldwide shut down schools in an effort to curb the transmission of COVID-19, affecting more than a billion students, globally.

The 'Girls' Education and COVID-19' regional, virtual convening aims to foster learning around on-the-ground experiences of, and research by, organizations based in Kenya, Tanzania, and Uganda, to understand how COVID-19 has affected girls' education in East Africa, and the near- and long-term efforts needed to ensure girls get back to school and learn.

The convening builds on a rapid desk review and key informant interview study, involving a range of key organizations in the East African region working on education and/or gender issues. Findings from this study will be drawn upon to spark conversation during this two-day, interactive, virtual meeting, during which participants will hear voices from across the region, and interact with like-minded, committed organizations to co-identify both the problems being grappled with in the region, and the solutions needed to support girls' education in this unprecedented time. As the study findings will demonstrate, with all the challenges brought about by the pandemic, come opportunities and hope.

The 'Girls' Education and COVID-19' Convening will provide a forum for participants to:

- Have a shared conversation around what we are learning about girls' education in the region in the time of COVID-19, what we need to do about it, and how;

- Collectively reflect and deliberate on what we are learning; and 


\section{Agenda}

Day 1 (July 12, 2021) 16:00-18:30, EAT

16:00-16:05 Opening, guidance on online participation, going through agenda and list of participants 16:05-16:15 Interactive online ice-breaker for introductions

16:15-16:25 Welcome remarks from Population Council (Chi-Chi Undie), Regional Education Learning Initiative [RELI] (Deborah Kimathi), and Echidna Giving (Dana Schmidt)

16:25-16:50 Background and “Understanding the Current Problems" Session

16:50-17:00 Break

17:00-17:15 “Understanding the Current Problems" Session continued and wrap-up

17:15-17:50 “Identifying the Gaps" Session

17:50-18:00 Break

18:00-18:25 "Illuminating Solutions" Session

18:25-18:30 Closing and reflections by Wellspring Philanthropic Fund (Joyce Malombe)

Day 2 (July 13, 2021) 16:00-18:30, EAT

16:00-16:10 Opening, guidance on online participation, summary of the previous day, going through agenda

16:10-16:15 A quick ice-breaker activity

16:15-16:45 "Illuminating Solutions" Session, continued

16:45-17:30 "Stock-taking" Session

17:30-17:40 Break

17:40-18:25 “Next Steps" Session

18:25-18:30 Closing remarks by Echidna Giving (Dana Schmidt) 


\section{List of invited organizations}

\begin{tabular}{|l|}
\hline Kenya \\
\hline African Population and Health Research Center \\
\hline Big Picture Learning \\
\hline Dignitas \\
\hline Education Development Trust \\
\hline Kakenya's Dream \\
\hline Plan International \\
\hline Population Council \\
\hline Usawa Agenda \\
\hline WISER International \\
\hline Tanzania \\
\hline AfricAid \\
\hline Camfed, Tanzania \\
\hline HakiElimu \\
\hline Milele Zanzibar Foundation \\
\hline Pastoral Women's Council \\
\hline Room to Read, Tanzania \\
\hline Uganda \\
\hline Educate! \\
\hline FAWE Uganda \\
\hline Foundation for Inclusive Community Help \\
\hline Girls to Lead Africa \\
\hline Girl Up Initiative Uganda \\
\hline Initiative for Social and Economic Rights \\
\hline Raising Voices \\
\hline Regional \\
\hline Amplify, Kenya \\
\hline FEMNET, Kenya \\
\hline Girl Up, Kenya \\
\hline GRIC, Kenya \\
\hline Human Rights Watch, Kenya \\
\hline ICRW Kenya/Uganda \\
\hline Impact(Ed) \\
\hline
\end{tabular}


Ideas. Evidence. Impact. 